\title{
WestVirginiaUniversity
}

THE RESEARCH REPOSITORY @ WVU

Graduate Theses, Dissertations, and Problem Reports

2008

\section{Obesity and spatial context in Appalachia}

Roberta J. Alt

West Virginia University

Follow this and additional works at: https://researchrepository.wvu.edu/etd

\section{Recommended Citation}

Alt, Roberta J., "Obesity and spatial context in Appalachia" (2008). Graduate Theses, Dissertations, and Problem Reports. 882.

https://researchrepository.wvu.edu/etd/882

This Thesis is protected by copyright and/or related rights. It has been brought to you by the The Research Repository @ WVU with permission from the rights-holder(s). You are free to use this Thesis in any way that is permitted by the copyright and related rights legislation that applies to your use. For other uses you must obtain permission from the rights-holder(s) directly, unless additional rights are indicated by a Creative Commons license in the record and/ or on the work itself. This Thesis has been accepted for inclusion in WVU Graduate Theses, Dissertations, and Problem Reports collection by an authorized administrator of The Research Repository @ WVU. For more information, please contact researchrepository@mail.wvu.edu. 


\title{
Obesity and Spatial Context in Appalachia
}

\author{
Roberta J. Alt \\ Thesis submitted to the \\ College of Arts and Sciences \\ at West Virginia University \\ in partial fulfillment of the requirements \\ for the degree of \\ Master of Arts \\ in \\ Geography \\ Robert Hanham, Ph.D., Chair \\ Alison C. Hanham \\ Timothy Warner, Ph.D. \\ Department of Geography
}

Morgantown, West Virginia

2008 


\title{
ABSTRACT \\ Obesity and Spatial Context in Appalachia
}

\author{
Roberta Jean Alt
}

The prevalence of obesity has increased substantially over the past 30 years. Obesity is a multi-factorial disorder, which is often associated with many other significant diseases such as diabetes, hypertension and other cardiovascular diseases, osteoarthritis and certain cancers. For these reasons, it is a complex health issue to address. The objective of this study is to identify the factors which are responsible for the spatial variation of adult obesity throughout the Appalachian region. In addition, preliminary examinations are made to identify potential associations between geographic variability in the prevalence of obesity and the characteristics of individuals and places with variable prevalence rates. Obese prevalence estimates were generated for all counties in Appalachia for adult males and females using data from the Behavioral Risk Factor Surveillance System (BRFSS). These data were used to create maps of obesity prevalence in Appalachia. Certain counties consistently experience higher prevalence of obesity for both genders. In areas with persistently high obesity prevalence rates, the burden is often highly localized among specific counties. A regression model was implemented to analyze the effect of a number of factors on obesity. Two significant contextual factors, employment change and labor force participation, were identified, even though they have not been addressed in the literature. The regression model results demonstrate poverty having a significant impact on female obesity, but no significant impact on male obesity. The regression model also found that urban-rural location is significant, but gender specific only for males in non-metro areas and small metro areas. 


\section{Acknowledgements}

The following thesis, while an individual work, benefited from the insights and direction of several people. First, my Thesis Chair, Dr. Robert Hanham was abundantly helpful and offered invaluable assistance, support and guidance. In addition, Dr. Robert Hanham provided timely and instructive comments and evaluation at every stage of the thesis project. Next, I wish to thank the supervisory committee: Dr. Timothy Warner and Alison Hanham. Each individual provided insights that guided and challenged my thinking, substantially improving the finished product. Also, I wish to express my love and gratitude to my beloved families; for their understanding \& endless love, through the duration of my studies and to my husband, Don, who believed in me when I didn't. Without his love and support I would not have come this far. Lastly, I wish to dedicate my work to my son, Jacob Peterson, he is the reason I started the masters program and the reason I wanted to finish. He is an inspiration to me and I want him to know that with dedication and hard work you can accomplish anything. 


\section{Table of Contents}

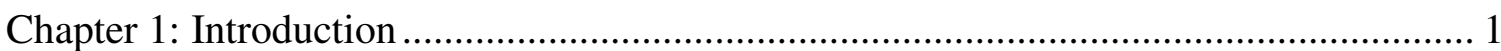

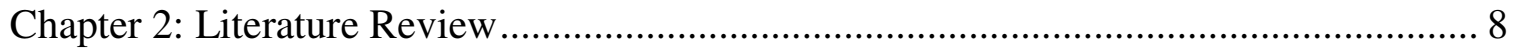

Compositional factors: individual behavior............................................................... 8

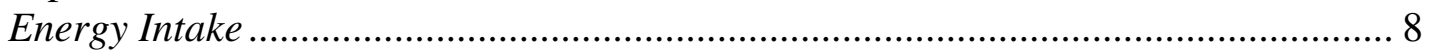

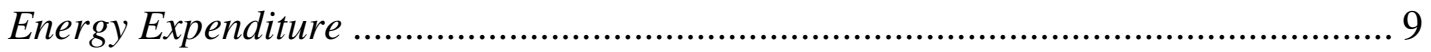

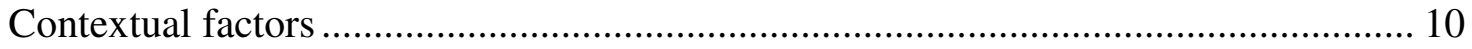

Socioeconomic status (SES) and income …………........................................... 11

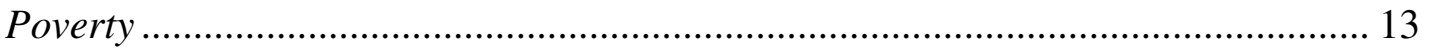

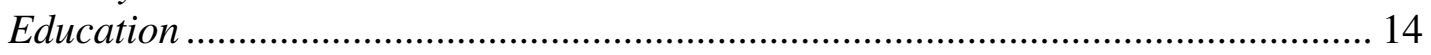

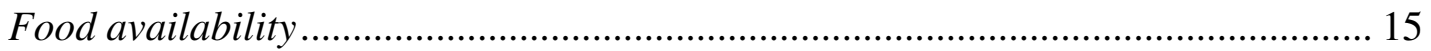

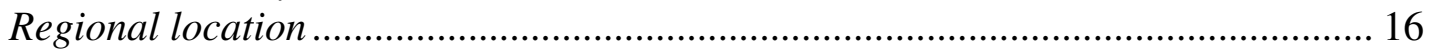

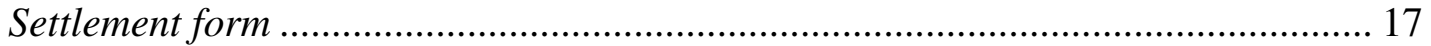

Chapter 3: Spatial Patterns of Obesity ………………….......................................... 18

Overall adult obesity prevalence by gender.............................................................. 19

Overall adult obesity male-female difference ................................................................ 22

Class 1 Adult obesity prevalence by gender .............................................................. 24

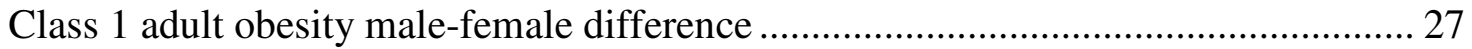

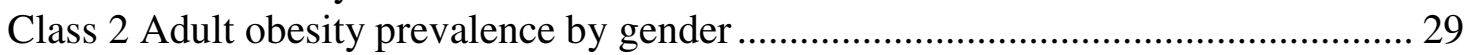

Class 2 adult obesity male-female difference …………............................................... 32

Chapter 4: Regression Model and Data ………………............................................. 34

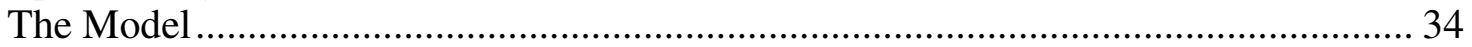

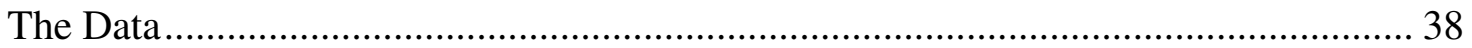

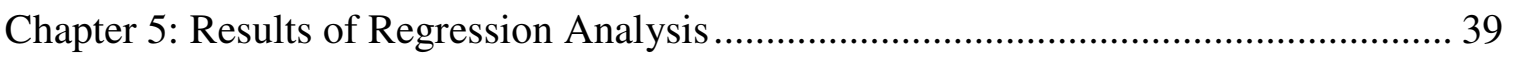

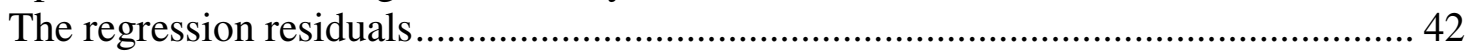

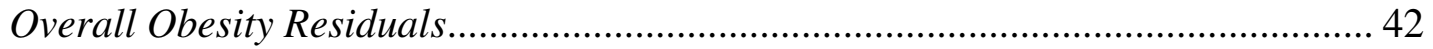

Class 1 Obesity Residuals ........................................................................... 46

Class 2 Obesity Residuals .......................................................................... 49

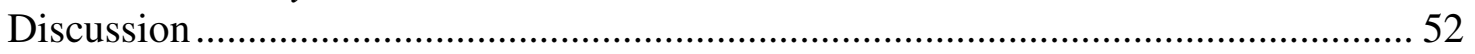

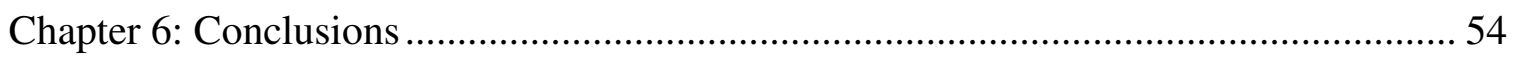

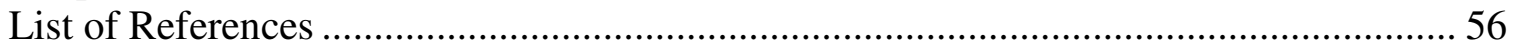




\section{List of Figures}

Figure 1: Percentage of overall obese males............................................................. 20

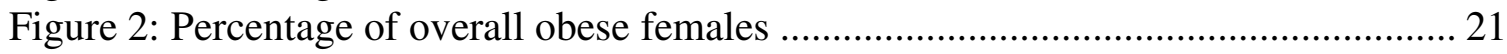

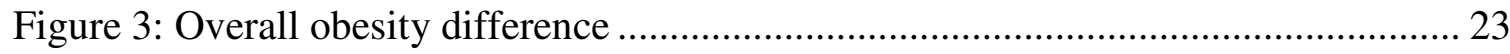

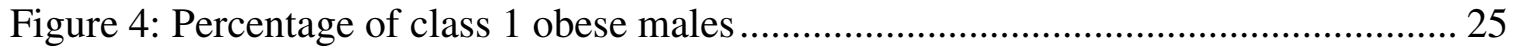

Figure 5: Percentage of class 1 obese females ............................................................. 26

Figure 6: Class 1 obesity difference for males-females................................................ 28

Figure 7: Percentage of class 2 obese males ............................................................. 30

Figure 8: Percentage of class 2 obese females ....................................................... 31

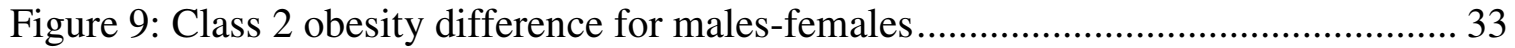

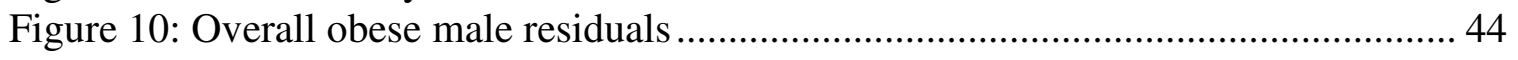

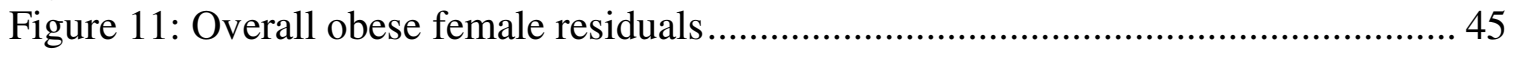

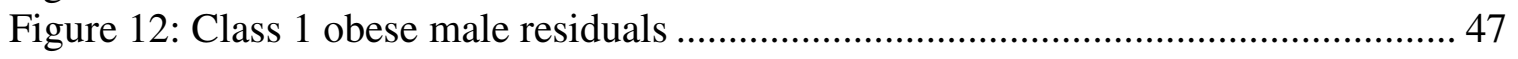

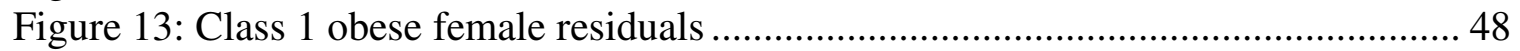

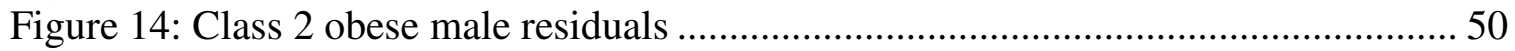

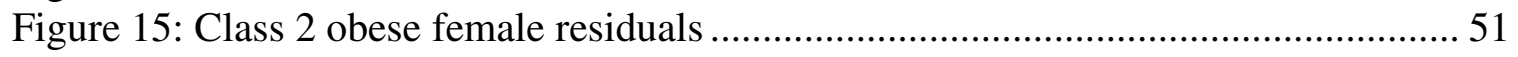




\section{Chapter 1: Introduction}

The goal of this research is to identify the factors which are responsible for the spatial variation of adult obesity throughout the Appalachian region. A regression model is used to accomplish this goal. Particular attention is given to the effect of urban-rural location and settlement form on obesity in the region.

Obesity is a complex, multi-factorial chronic, metabolic disease caused by multiple and intricate factors. Therefore, it is a convoluted health issue to address. It results from a complex interaction of genetic, physiologic, behavioral, psychological and environmental factors causing a chronic imbalance between energy intake and energy expenditure. Energy intake and energy expenditure is a function of resting metabolic rate, the thermal effect of food, and the energy expended in physical activity (American Obesity Association, 2004; Holm et al., 2001). Obesity can arise only when energy intake exceeds energy expenditure.

During the past two decades the prevalence of obesity has reached epidemic proportions and is increasing in both men and women, in all age groups, and in all racial/ethnic groups (Flegal et al., 2002). Severe obesity is increasing the fastest in American adults (RAND, 2004), and three out of ten United States adults are obese (Crespo \& Arbesman, 2003). Contaldo \& Pasanisi (2003) stated that obesity is one of the top 10 risk conditions in the world. Due to this, obesity is a major factor when considering morbidity and mortality and has become one of the single most important 
health risks related to diet in the United States (Nestle, 2000). Obesity is a metabolic disease that has continued to increase in prevalence since 1960, and affects fifty nine million Americans: nearly one-quarter of all adults and one in five children (Fox, 2004). According to an estimate made by James et al. (2001), the United States is one of the countries with the highest obesity rates. The Center for Disease Control (CDC) and Prevention 1999-2000 National Health and Nutrition Examination Survey (NHANES) found sixty four percent of United States adults were either overweight (33\%) or obese (31\%) (Center for Disease Control, 2004; Fox, 2004; Ewing et al., 2003).

Obesity is the second leading cause of unnecessary deaths each year, approximately 400,000 in 2004, up from 300,000 in 1990 (Fox, 2004; Ewing et al., 2003; Mokdad et al., 2001). Sturm and Wells, (2001) stated that the prevalence of obesity is higher than that of poverty, daily smoking, or heavy drinking. Prior to 2005 the Center for Disease Control estimated that 400,000 people died every year from weight-related causes. This estimate was revised downward to 25,000 deaths in January 2005. However, this downward revision has been strongly disputed, causing a great deal of debate among medical researchers and public health officials since then (Milloy, 2005).

Currently, adult obesity appears to be growing unabated, while an increase in overweight children points to an even greater prevalence of adult obesity and its associated comorbidities (Mcinnis, 2003; James et al., 2001; U.S. Department of Health and Human Services, 2000). Even the average weight of a 10-year-old has increased about 11 pounds in the last forty years (Reuters, 2004). From 1988-1994 12- through 19year-olds increased from $5 \%$ to $11 \%$ (Ogden et al., 2002). Nearly twelve percent of the 
United States adults, aged sixty five years and older, are currently considered to be obese, a figure likely to increase to twenty percent by 2050 (Reuters, 2004). Because of these statistics, researchers fear what kind of effect the obesity epidemic will have on the next generation of adults (Ogden et al., 2002).

Numerous studies have shown that regular physical activity is good for overall health. Incorporating physical activities into a daily routine will aid in decreasing the risk for colon cancer, diabetes, and high blood pressure. Despite the health benefits of physical activity, seventy four percent of the United States adults do not get enough physical activity to meet public health recommendations. One in four United States adults remains completely inactive during their leisure time (Ewing et al., 2003; Humpel et al., 2002). Technology has contributed to inactivity by creating many time and labor saving products. Some examples include cars, elevators, computers, dishwashers, and televisions. Cars are often used to run short distance errands instead of individuals walking or riding a bicycle. As a result, these recent lifestyle changes have reduced the overall amount of energy expended in our daily lives. Obese individuals suffer from poor general health, depression, personal uncertainty, and low life satisfaction due to a decline in their physical activity levels (Burton et al., 2003; Holm et al., 2001; Ford, 2001).

Obesity has a detrimental impact on the health, social characteristics and finances of the United States population. A study by the CDC (2005) found the total cost of obesity in the United States in 2000 estimated about $\$ 117$ billion. Another study implemented by the CDC and the Research Triangle Institute (RTI) International in the United States showed obesity attributing to medical expenditures reaching $\$ 75$ billion in 
2003. Taxpayers finance about half of these costs through Medicare and Medicaid programs (Ma, 2004; Center for Disease Control, 2004). Also, obesity is linked to higher health care costs than smoking or drinking (RAND, 2004).

Obesity is a latent factor significantly related to triggering the onset of many chronic conditions. It is found to be a risk factor for heart and gallbladder disease, diabetes mellitus, hypertension, osteroarthritis, sleep apnea, cardiovascular disease, congestive heart failure, stroke, dyslipidemia, arthritis-related disabilities, hyperinsulinemia, insulin resistance, gallstones, gastroesophageal reflux disease, and cancers of the colon, prostate, breast, uterus, cervix, ovary, stomach, endometrium and uterin lining. Obesity has also been found to be associated with complications in pregnancy, high blood pressure and cholesterol, menstrual irregularities, hirsutism, stress incontinence, psychological disorders, and increased surgical risk (Crespo \& Arbesman, 2003; Ford et al., 2001; Nestle, 2000; Observer, 2004; PersonalMD, 1998, Reeves et al., 2008; Sciamanna et al., 2000). According to Ferraro et al., (2002) obesity is associated with higher levels of both upper- and lower-body disability. Obese individuals experience social stigmatization, discrimination and prejudice in social, employment and academic endeavors (Ford et al., 2001; Sciamanna et al., 2000).

Due to major concerns about health hazards caused by obesity, the World Health Organization (WHO) devised a standardized classification of obesity based on Body Mass Index (BMI) (James et al., 2001 \& RAND, 2004), which for the first time allowed standard comparisons of obesity and overweight prevalence worldwide. BMI is calculated by dividing a person's weight in pounds by height in inches squared and 
multiplied by 703. In 1998, the National Institutes of Health (NIH) also endorsed the use of BMI for defining obesity and it has since become the most frequently utilized measurement in the assessment of obesity. The WHO also agreed upon a number of classes in order to assess the health hazards associated with different degrees of obesity. These BMI classes (obese class 1 is 30.0 to 34.9 , obese class 2 is 35.0 to 39.9 and obese class 3 is $>39.9$ ) are commonly used classifications for the assessment of obese weight status (Halverson et al., 2004).

Previous studies have shown that increased BMI is known to increase the risk of adenocarcinoma of the esophagus, endometrial cancer, kidney cancer and postmenpausal breast cancer in women. Menopausal status is also a key factor in the relation between $\mathrm{BMI}$ and risk of breast cancer, endometrial cancer and colorectal cancer among women. Furthermore, hormonally related cancers such as those of the breast and endometrium have been among those most consistently associated with BMI (Reeves et al., 2008). Obese females have shown higher incidence of deaths with cancer of the breast, uterus, cervix and ovary (Reuters, 2002(a)). For both men and women obesity is a risk factor for colon cancer and with deaths attributed to the disease topping 46,000 annually (Personal MD, 1999; Reuters, 2002(b)). In men, the heaviest individuals are more likely to die from cancer of the stomach and prostate. Reuters, (2003) estimated that more than 90,000 cancer deaths each year could be avoided if every American maintained a healthy weight.

Both overweight and obese women are less active than men within the same BMI category (Adams et al., 2003). In a study done by Ewing et al. (2003), they found 
markedly fewer women than men performed high-intensity physical activities. Holm et al. (2001) found that women gain weight many years before their male counterparts. According to Burton et al. (2003) males were more likely than females to describe enjoyment of physical activity participation.

The steady increase in the prevalence of obesity in both developed and developing societies during the past decade varies across population groups (Monterio et al., 2001). Although the nature of obesity-related health risks is similar in all populations, the specific level of risk associated with a given level of obesity may be different depending on age, gender and race. It has been shown that obesity increases steadily with age for both men and women (American Obesity Association, 2004; Bernstein et al., 2003). James et al. (2001) found that in most countries, women had higher BMIs than men. This may be because women are eating 335 more calories per day than they did in 1971, while adult men have upped their daily intake by 168 calories (Newman, 2004).

Race and ethnicity are also very important factors when identifying trends in obesity. In recent years in the United States, with the exception of Asian-Americans, the prevalence of overweight and obesity is higher in racial-ethnic minority populations. Hispanic populations are more likely to have higher prevalence of overweight, while African American populations are more likely to have higher obesity prevalence (Halverson et al., 2004; Casper et al., 2001). Furthermore, the prevalence of obesity comorbidities is much higher in African Americans compared to Caucasians (Paeratakul et al., 2002). Also, obesity is $36 \%$ higher for African American women and 33\% higher 
for Mexican American women than among Caucasians women (22\%) (Crespo \& Arbesman, 2003; Casper et al., 200).

The study area for this research is Appalachia. Appalachia is an extensive region, which is both socioeconomically and geographically diverse. Furthermore, it is a region that contrasts markedly from the rest of the United States.

Appalachia includes all of West Virginia and parts of twelve other states:

Alabama, Georgia, Kentucky, Maryland, Mississippi, New York, North Carolina, Ohio, Pennsylvania, South Carolina, Tennessee, and Virginia. About twenty three million people live in the 410 counties of the Appalachian region. Forty-two percent of the region's population is rural, compared with twenty percent of the national population. The poverty rate in Appalachia is 15 percent -- just two points above the national average (National Center for Policy Ananlysis, 1999). The region's economic fortunes were based in the past mostly on extraction of natural resources and manufacturing. The modern economy of the region is gradually diversifying, with a heavier emphasis on services and widespread development of tourism, especially in more remote areas where there is no other viable industry. Coal still remains an important resource, but it is not a major provider of jobs.

This remainder of this thesis is organized as follows: Chapter 2 presents a review of the literature on obesity; Chapter 3 provides detailed descriptions of maps which show the geographic variation in obesity in Appalachia; Chapter 4 discusses the research design and model; Chapter 5 presents the results of the regression analysis; Chapter 6 presents some final conclusions of the research. 


\section{Chapter 2: Literature Review}

This chapter provides a review of the literature regarding factors that are responsible for obesity. The literature is divided into two sections: 1) the role of individual behavior specifically relating to energy intake and energy expenditure (compositional factors) and 2) the role of socioeconomic context within which people live (contextual factors).

\section{Compositional factors: individual behavior}

\section{Energy Intake}

Epidemiologists suggest that obesity is largely due to modifiable individual behaviors related to unhealthy dietary habits involving high calorie foods eaten in large portions. Researchers have suggested that an individual's average energy consumption has risen and/or activity levels have declined (Adams et al., 2003; Bernstein et al., 2003; Binkley et. al., 2000; French, 2003; Hill and Peters, 1998; Holm et al., 2001; James et al., 2001; Jeffery et al., 2003; Ravussin and Danforth, 1999; Thorogood, 1998)

According to Binkley et al (2000), energy intake has increased in the United

States. Also, the United States data on food consumption suggests that per capita energy intake rose from 3300 to 3800 calories per day between 1977 and 1994, a fifteen percent increase. Promotions, pricing, and availability all encourage Americans to eat more food, not less. The food industry spends about $\$ 11$ billion annually on advertising and in 1998 McDonalds's spent just over a billion dollars in promotion costs (Nestle \& Jacobson, 
2000). Ma, (2004) found consumption of $1876 \mathrm{kcal}$ per person in 1977-1978 and 2006 kcal per person in 1994.

\section{Energy Expenditure}

Our society has become very sedentary, and many adult Americans have not been meeting federal physical activity recommendations. The physical activity recommendations include thirty minutes of moderate physical activity at least three times per week. In 1997, only fifteen percent of adults performed the recommended amount of physical activity, and forty percent of adults engaged in no leisure-time physical activity. Previous studies have shown that seventy four percent of adults in the United States do not get enough physical activity to meet public health recommendations, and about one in four United States adults remains completely inactive during their leisure time (Crespo \& Arbesman, 2003; Ewing et al., 2003; Frank et al., 2004; US Department of Health and Human Services, 2000; US Department of Health and Human Services, 2001)

Numerous studies have shown that women generally are less active than men of all ages. Middle-aged and older women, in particular, engage in little or no exercise (Thorogood, 1998). Furthermore, obese women are less active than men within the same BMI category (Adams et. al., 2003). Also, African Americans and Hispanics are generally less physically active than their white counterparts. In addition, older adults who live in unsafe neighborhoods are significantly more likely to report being physically inactive which also contributes to high levels of obesity (Andersen et. al, 2001). Researchers have found that the major barriers most people face when trying to increase 
physical activity are lack of time, lack of access to convenient facilities, and lack of safe environments in which to be active.

\section{Contextual factors}

An individual's body weight and body composition are determined by interactions between the environment and genetics. Some individuals can avoid obesity in unsupportive environments by maintaining a pattern of healthy behaviors (Hill \& Peters, 1998; Ma, 2004). However, the current epidemic of obesity is caused largely by an environment that promotes excessive food intake and discourages physical activity. Our environment is characterized by an essentially unlimited supply of convenient, relatively inexpensive, highly palatable, energy-dense foods, coupled with a lifestyle requiring only low levels of physical activity for subsistence (Hill \& Peters, 1998; Holm et al, 2001; Ravussin \& Danforth, 1999). Also, in our society eating habits exacerbated by advertising, especially the over-consumption of high-caloric and fatty foods, promote the high incidence of obesity in all age groups. Compounding this is a growing trend in the United States toward larger portions of foods (Ma, 2004; Holm et al, 2001). Friedman, (2003) stated that more than half of the United States population is now overweight or obese and that the environment has contributed to this public health problem.

There is growing interest in how physical inactivity, obesity, and related chronic health problems are affected by environmental factors. Low levels of physical activity are associated with an increased risk of obesity, and our current environment tends to discourage physical activity. Advances in technology and transportation in our modern cities have reduced the need for physical activity in daily life (Larkin, 2003; Owen et al., 
2004). The appeal of electronic games, television, and computers has increased the time spent in sedentary pursuits among children and adults a like (Hill \& Peters, 1998). Our modern environment has allowed these conditions to increase at alarming rates and become highly pressing health problems for our nation (U.S. Department of Health and Human Services, 2001). Urban sprawl, for example, increases traffic and destroys open space which limits individuals from access to large open and safe spaces where they can engage in physical activities (Larkin, 2003).

\section{Socioeconomic status (SES) and income}

Socioeconomic status (SES) depends on a combination of variables, including occupation, education, income, wealth, and place of residence. Some researchers have found that the prevalence of obesity is significantly higher among individuals with lower levels of education, income and occupational prestige when compared to their counterparts because typically they report little or no physical activity and high calorie diets (Adler \& Ostrove, 1999; Bernstein et al., 2003; Burton et al., 2003; Kahn et al., 1991; Ma, 2004; US Department of Health and Human Services, 2001). Reeves et al. (2008) found women with a higher BMI tended to come from a lower socioeconomic class and had more children than women with a lower BMI. For all racial and ethnic groups combined, women of lower SES are approximately fifty percent more likely to be obese than those with higher SES. Binkley et al. (2000) found that women with higher SES are more concerned with their physical appearance. Men are about equally likely to be obese whether they are in a low or high socioeconomic group (U.S. Department of Health and Human Services, 2001; Drewnowski and Specter, 2004). Also, according to 
Sobal and Stunkard (1989), in developed Western industrialized societies obesity was six times more prevalent among women of lower SES than among those of upper SES.

Current studies show that there is a clear inverse relationship in most societies between the level of SES and the prevalence of obesity. Obesity is six times more prevalent among women of lower SES than among those of upper SES (Sobal \& Stunkard, 1989). Also, the socioeconomically disadvantaged are less likely to engage in recreational physical activity (RPA) and more likely to describe poor health experiences, limited exposure, fewer activity-promoting cognitions, fewer anticipated benefits, less social support, and barriers of inconvenient access and low personal functioning. In contrast, people of higher SES are more likely to engage in RPA and also more likely to be exposed to opportunities, activity-promoting cognitions, and social, emotional, and lifestyle benefits (Burton et al., 2003).

Adults from lower socioeconomic backgrounds are more likely to perceive healthrelated behaviors as compromising quality of life, are least knowledgeable about healthrelated recommendations and guidelines, and are less likely to perceive their current behavior as health compromising. Low socioeconomic groups are also less likely to attribute illness to personal behaviors, to report personal health-related behavior change as effective, and to value healthy lifestyle activities including getting regular exercise. These individuals do not perceive a personal need to engage in physical activity for health benefit. Furthermore, Burton et al.'s (2003) study found that the socioeconomically disadvantaged participants did not receive encouragement and companionship for recreational physical activity. 


\section{Poverty}

Obesity is strongly associated with poverty, even in developing countries. This may relate to social circumstances and cultural differences, which alter behavior. Also, the choice of an energy-dense diet may be determined by the relative cheapness of processed foods, the constant bombardment of food advertising, provision of large portion sizes as a marketing technique, and the immediate availability of fast foods everywhere mean that individuals have to constantly battle against the natural tendency to eat (James et al., 2001). Obesity is becoming more and more prevalent among poor women in developing nations. This may be due to lack of knowledge about health and trouble acquiring more expensive healthier foods (Richwine, 2004). Furthermore, James et al. (2001) found that the poverty stricken gain enjoyment from watching television because this activity requires less initiative and financial resource than engaging in a greater variety of social and leisure time activities that require more energy.

Furthermore, many health disparities in the United States are linked to inequalities in education and income. First, the highest obesity rates occur among population groups with the highest poverty rates and the least education. Second, there is an inverse relation between energy density and energy cost, such that energy-dense foods composed of refined grains, added sugars, or fats may represent the lowest-cost option to the consumer. Third, the high energy density and palatability of sweets and fats are associated with higher energy intakes. Fourth, poverty and food insecurity are associated with lower food expenditures, low fruit and vegetable consumption, and lower-quality diets (Drewnowski \& Specter, 2004). 
According to the Pan American Health Organization, obesity is increasingly being seen as a feature of the poor (James et al, 2001). Typically, individuals who live in poverty have limited lifestyle choices and therefore may be more susceptible to disease risk factors than those individuals with more economic resources. In addition, individuals who live in poverty are less likely to have access to high quality healthcare, education, and health information (Halverson et al., 2004).

\section{Education}

While educational attainment is linked to income earning ability, it may also encompass factors that reflect the broader values associated with a healthy population (Halverson et al., 2004). Many researchers have found that education is negatively correlated with obesity and seems to be associated with behaviors such as diet and exercise. In general, researchers who have examined education discovered individuals with little or no education are typically less active than educated individuals (Kahn et al., 1991; James et al., 2001; Burton et al., 2003; Ford et al., 2001; Ewing et al., 2003; Bernstein et al., 2003; US Department of Health and Human Services, 2000). Ewing et al. (2003) also noted that education was positively associated with minutes of walking and being physically active in general and BMI was higher for the less educated. Drewnowski \& Specter (2004) found that among women, higher obesity rates tend to be associated with low education levels as compared to their male counterparts.

Obesity is highest among individuals who had less than a high school education and is lowest among those who have more than a high school education (Crespo \& Arbesman, 2003). James et al. (2001) found a clear inverse relationship in most societies 
between the level of education and the prevalence of obesity. Sciamanna et al. (2000) studied individuals who received advice to lose weight. They found that forty percent more individuals, with at least some college education, received advice to lose weight. Their study also showed that individuals with less than a high school education did not receive any advice to lose weight.

\section{Food availability}

Access to food plays an important role in determining an individual's lifestyle.

Being able to access lower-fat foods is important for individuals and their consumption of healthy foods (Frenn \& Malin, 2003). Also, prices and incomes affect food choices, dietary habits, and diet quality. Income disparities have more of an effect on diet quality, forcing the socioeconomically disadvantaged to purchase energy-dense foods composed of refined grains, added sugars, or fats because it represents the lowest-cost option (Drewnowski \& Specter, 2004). Whereas "good" diets are associated with higher education and incomes, "poor" diets are associated with low education because healthier diets cost more and are beyond the reach of many low-income families. Data from the Bureau of Labor Statistics indicate that income disparities have an effect on diet quality, and to achieve a healthy diet it may be necessary to spend more money (Drewnowski \& Specter, 2004).

Furthermore, Hill and Peters (1998) found a growing trend in the United States toward larger portions of food. Based on income levels, poverty stricken areas of cities have fewer food establishments, restaurants, and grocery stores that serve healthy foods. 
In addition, white neighborhoods have supermarkets with a variety of healthy foods and these are four times more prevalent than in black neighborhoods (Frank et al., 2004).

Environmental influences on eating behavior include the changing nature of the food supply, increased reliance on foods away from home, food advertising, marketing and promotion and food pricing. The food industry spends approximately thirty three billion dollars annually on advertising and trade shows (Nestle, 2000). Foods away from home captured forty percent of total food spending in 1995. Individuals of lower socioeconomic status may place greater importance on perceived value, whereas those who are mainly concerned about health and nutrition may place greater importance on the nutritional quality of foods. However, in general, people choose the tastier and cheaper foods which are available nearly everywhere (French, 2003 and Hill and Peters, 2004).

\section{Regional location}

Studies have shown that adults in northeastern and southern states of the US tend to be less active than adults in north-central and western states (US Department of Health and Human Services, 2000). James et al.'s (2001) global study on obesity found that the prevalence rates for obese people are different in each region, with the Middle East, Central and Eastern Europe, and North America having higher prevalence rates. Furthermore, in China, Europe and the Republic of Ireland, obesity rates have increased due to a markedly improved economy allowing wealthy individuals to purchase expensive high fat foods (Holm et al., 2001). In non-Western developing agricultural societies, obesity among men, women and children is rare, presumably because of insufficient food and also because of high levels of energy expenditure. In these 
societies, the prevalence of obesity increases with rising wealth and increasingly available food sources.

\section{Settlement form}

Ewing et al. (2003) found that the probability of being obese, and to a lesser extent of being physically active, is significantly associated with the overall urban form of the county in which a person lives. An increasing body of evidence shows that the physical design of the places where people live and work affects their overall travel choices and how much they walk or bike for utilitarian travel. Both sprawling and urban structures contribute to obesity in different ways.

McCann and Ewing (2003) found a direct relationship between urban sprawl and individuals with a high BMI and between sprawl and chronic disease. Furthermore, they found that individuals living in counties with urban sprawl are likely to weigh more and have greater prevalence of hypertension. In areas of sprawl, people tend to live far from destinations, causing them to drive because it is unsafe to walk or ride a bicycle. People residing in areas of sprawl tend to have higher blood pressure and are more likely to have diabetes. Individuals who live in more mixed use neighborhoods are less likely to be obese, drive less, and walk more (Frank et al., 2004; McCann \& Ewing, 2003). According to Larkin (2003) modern cities can also be blamed for obesity prevalence. The cities are designed around the automobile, providing only busy streets and roaring expressways, prohibiting physical activity. Therefore, many individuals do not have access to safe and activity-friendly environments. 


\section{Chapter 3: Spatial Patterns of Obesity}

Obese prevalence estimates were generated for all counties in Appalachia for adult males and females using data from the Behavioral Risk Factor Surveillance System (BRFSS) (Halverson et al., 2004). The BRFSS is a telephone-based nationwide survey conducted by state health departments across the country (Pickle, \& Su, 2002). The survey is designed to "collect uniform, state-specific data on preventive health practices and risk behaviors that are linked to chronic disease, injuries and preventable infectious disease" (Halverson et al., 2004 and US Department of Health and Human Services, 1999). Although the BRFSS began in 1984, county identifiers were not universally provided until 1993. Therefore, sub-state areas cannot be analyzed using data prior to 1993. The target population for the BRFSS survey is the adult (aged 18 and older) noninstitutionalized population of each state. A two-stage random-digit telephone sampling protocol is used to contact households, and a third stage randomly selects a single eligible adult from within each sampled household (Halverson et al., 2004).

This chapter presents a series of maps of obesity prevalence in Appalachian counties by gender. Obesity data were aggregated for the years from 1993 though 1997, which greatly reduces the effect of short-term fluctuations in the data. Maps are shown for overall obesity (BMI of 30.0 or more), obesity class 1 (BMI between 30.0 and 34.9) and obesity class 2 (BMI between 35.0 and 39.9). Maps of obesity class 3 (BMI of 40.0 or more) are not presented here because the number of people in this class is very small and the prevalence rates may be unreliable at the county scale. 


\section{Overall adult obesity prevalence by gender}

Maps showing the geographic distributions of overall obesity prevalence for males and females are shown in Figures 1 and 2. There is considerable variation in obesity prevalence among Appalachian counties for both genders. Obesity prevalence estimates ranged from $10 \%$ to $27 \%$ among males and $7 \%$ to $25 \%$ among females. For both genders, clusters with high rates occur primarily in the central and northernmost parts of Appalachia. Rates tend to be lowest for males throughout most of the southern part of Appalachia. Lowest rates for females also tend to occur in the south, but in a more restricted part of the region than for males. 


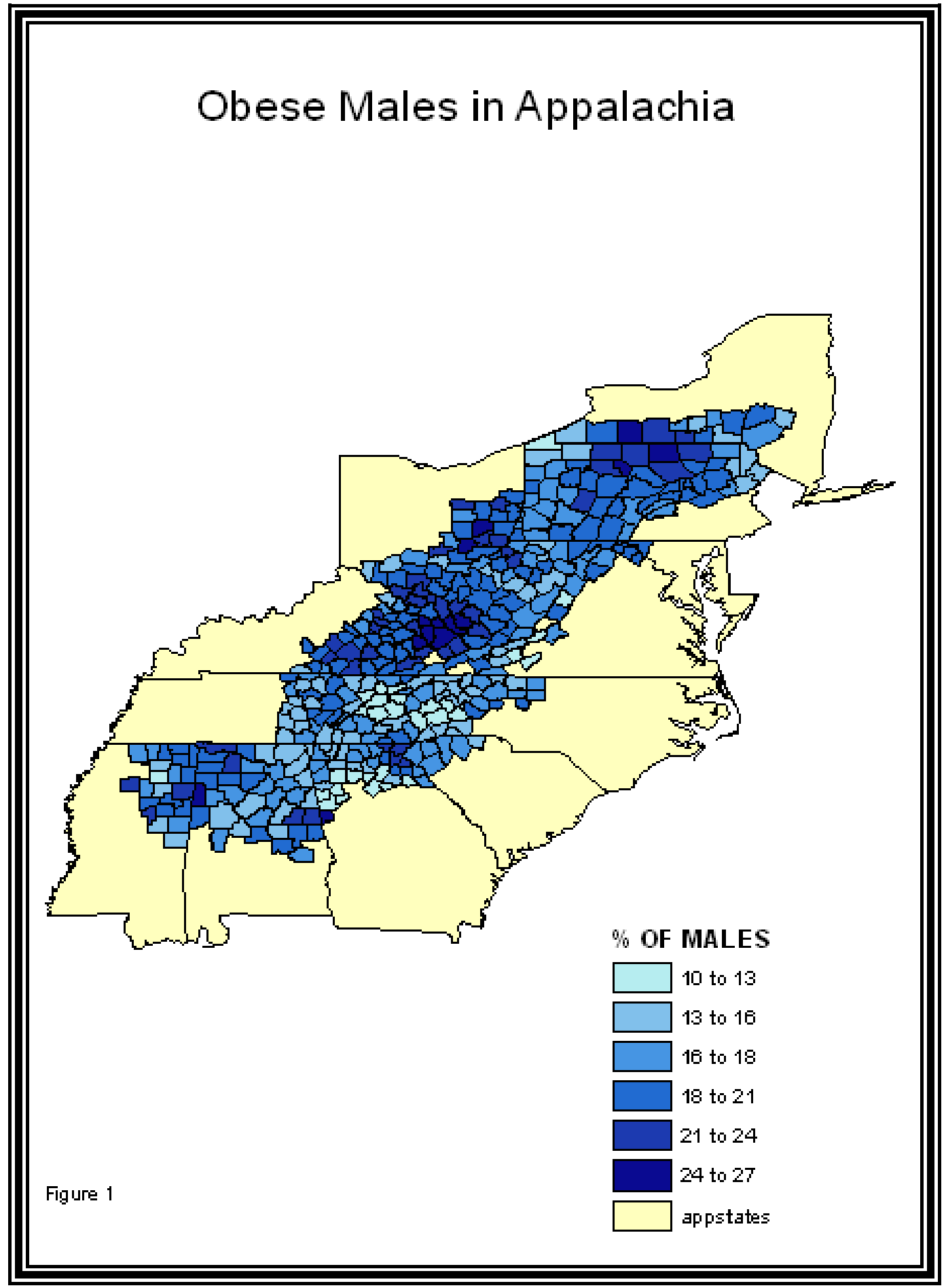

Figure 1: Percentage of overall obese males 


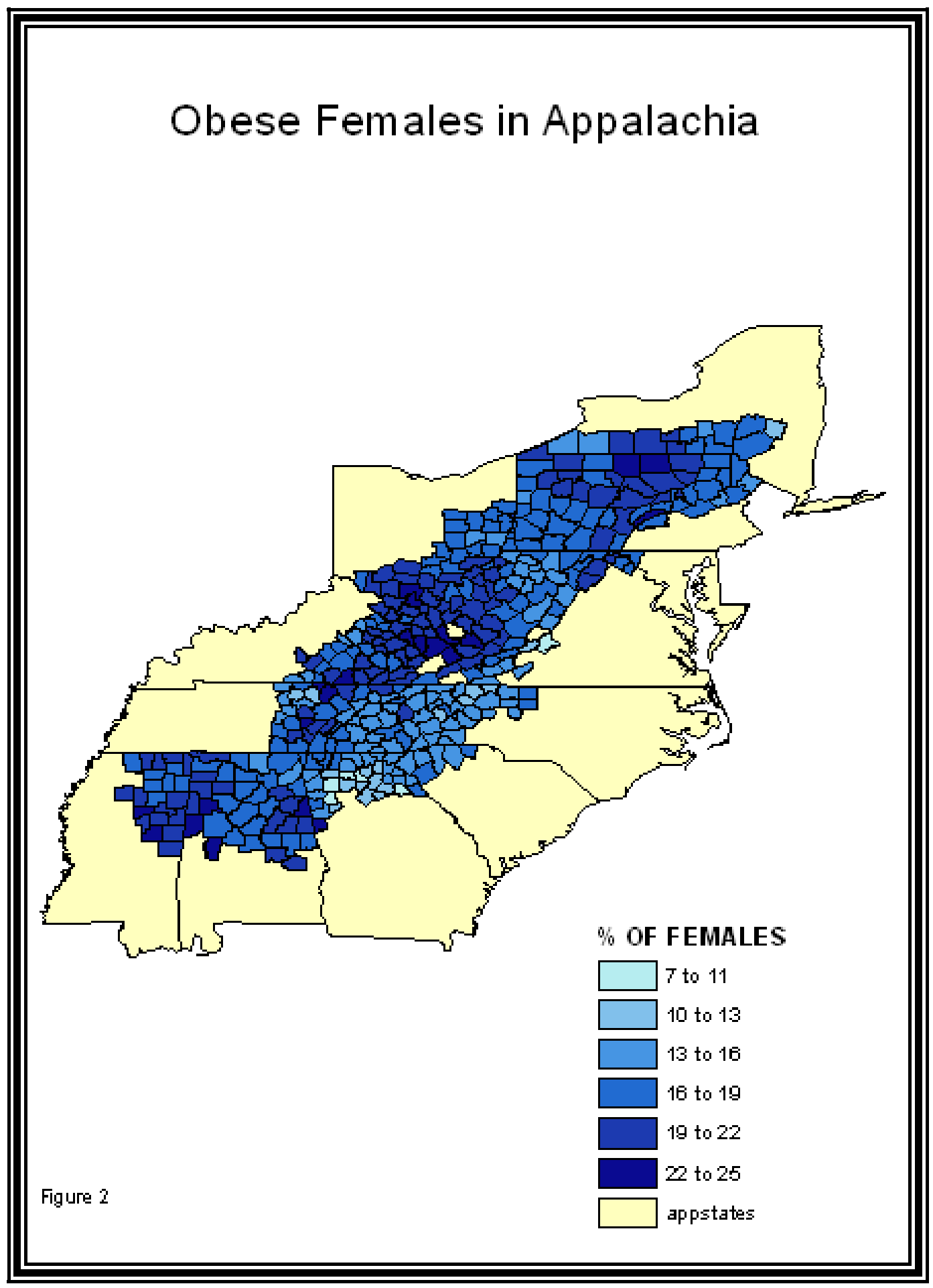

Figure 2: Percentage of overall obese females 


\section{Overall adult obesity male-female difference}

The difference in overall obesity rate between males and females is calculated by subtracting the female rate from the male rate. Figure 3 shows a geographic distribution of adult obesity difference ranging from $-8 \%$ to $10 \%$ throughout Appalachia. Areas with particularly high obesity prevalence among males relative to females occur in northern Georgia, western North and South Carolina, western Kentucky, southeastern Ohio and the border between Pennsylvania and New York. Areas with particularly high obesity prevalence among females relative to males occur in central West Virginia, western Pennsylvania and much of Alabama, Mississippi and Tennessee. 


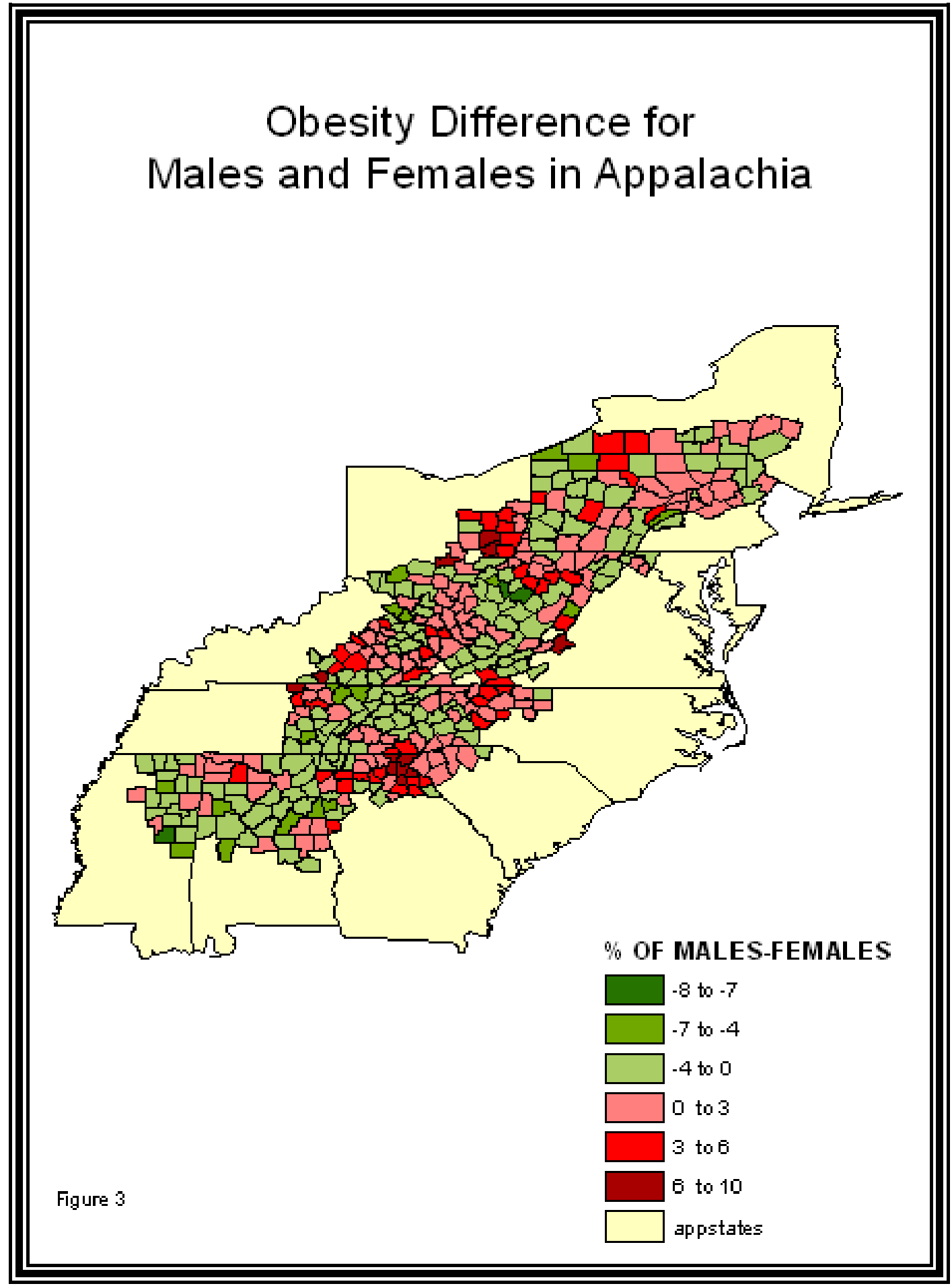

Figure 3: Overall obesity difference 


\section{Class 1 Adult obesity prevalence by gender}

Class 1 obesity prevalence rates (BMI of 30.0 to 34.9) for adult males and females are shown in Figures 4 and 5. The geographic distributions of class 1 obesity prevalence ranged from $7 \%$ to $24 \%$ among males and $5 \%$ to $21 \%$ among females. Areas of high prevalence for males occur in central Appalachia, southeast Ohio and north-central Pennsylvania/southern New York. Areas of high prevalence for females occur in central Appalachia, north-central Pennsylvania/southern New York and Alabama/Mississippi. Lowest rates for males occur in western Pennsylvania, throughout the south. Lowest rates for females occur in Ohio, northern West Virginia and in Georgia/North Carolina/Tennessee. 


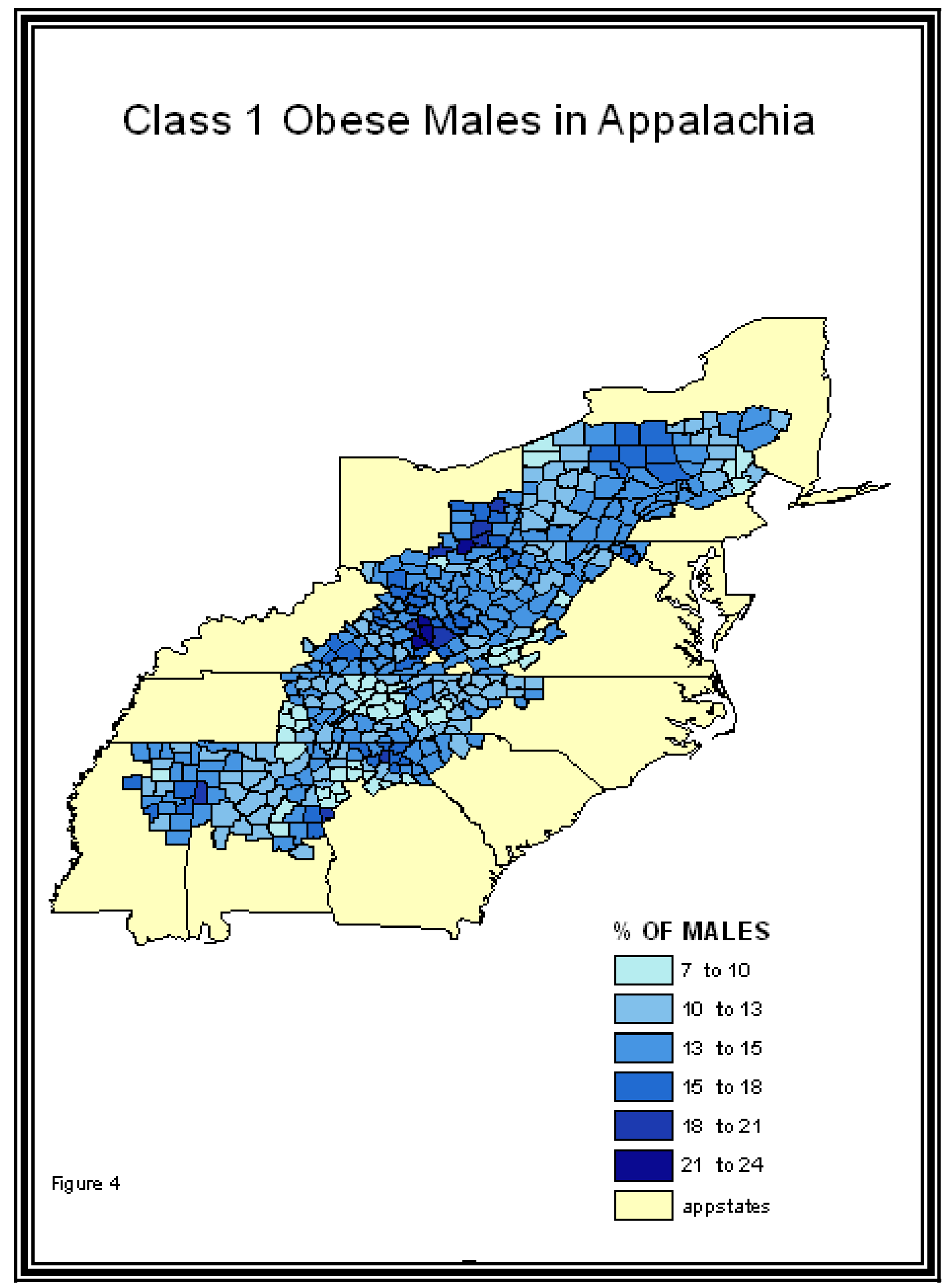

Figure 4: Percentage of class 1 obese males 


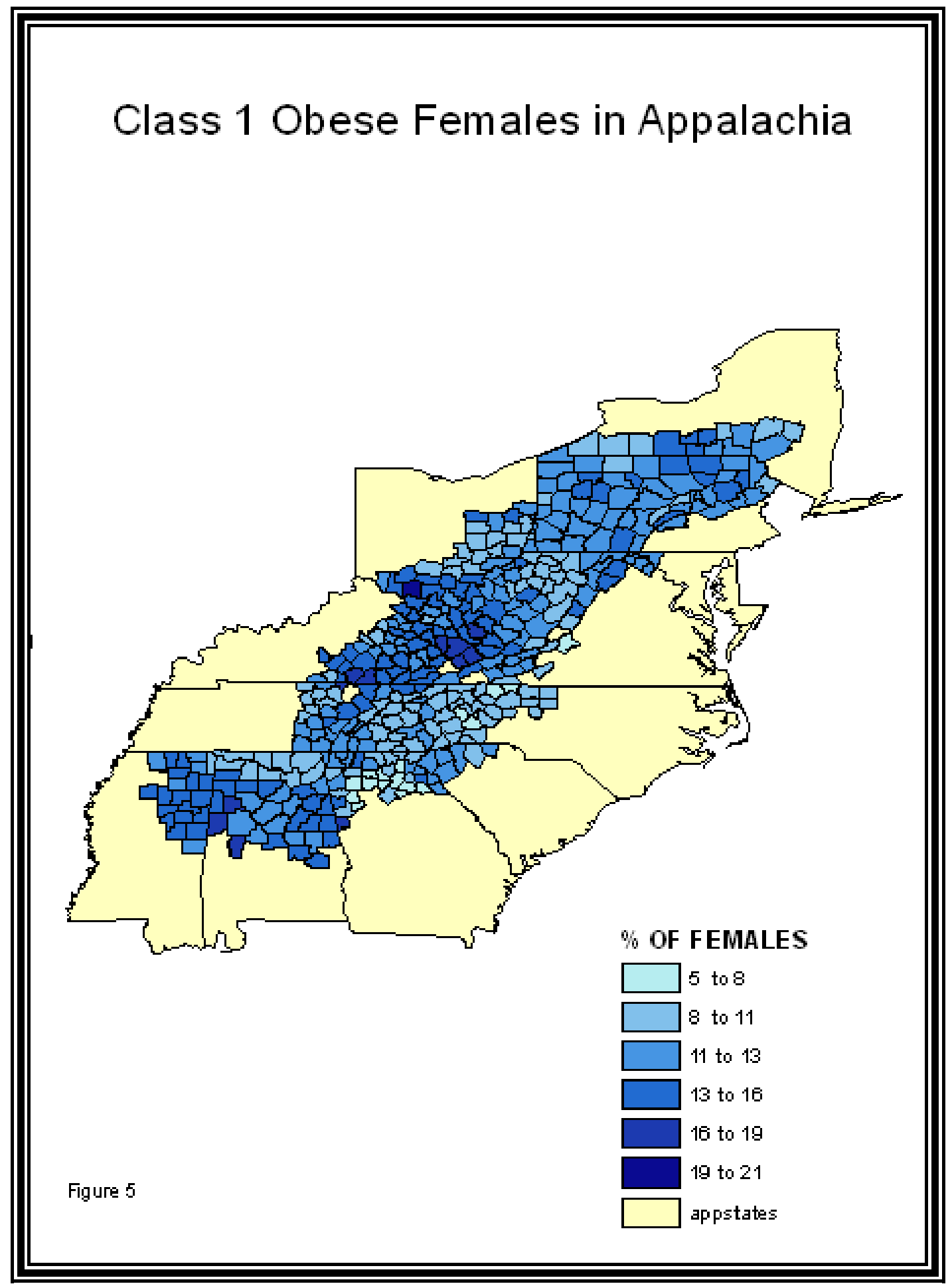

Figure 5: Percentage of class 1 obese females 


\section{Class 1 adult obesity male-female difference}

The class 1 obesity difference ranges from $-8 \%$ to $13 \%$ in Figure 6 . The map shows that class 1 male obesity is higher than class 1 female obesity for the great majority of counties in Appalachia. Areas with high obesity prevalence among males relative to females occur in northern Georgia, southeastern Ohio, northern West Virginia and the border between Pennsylvania and New York. Areas with high obesity prevalence among females relative to males occur in western and eastern Pennsylvania, Alabama, Tennessee and southwestern Virginia. 


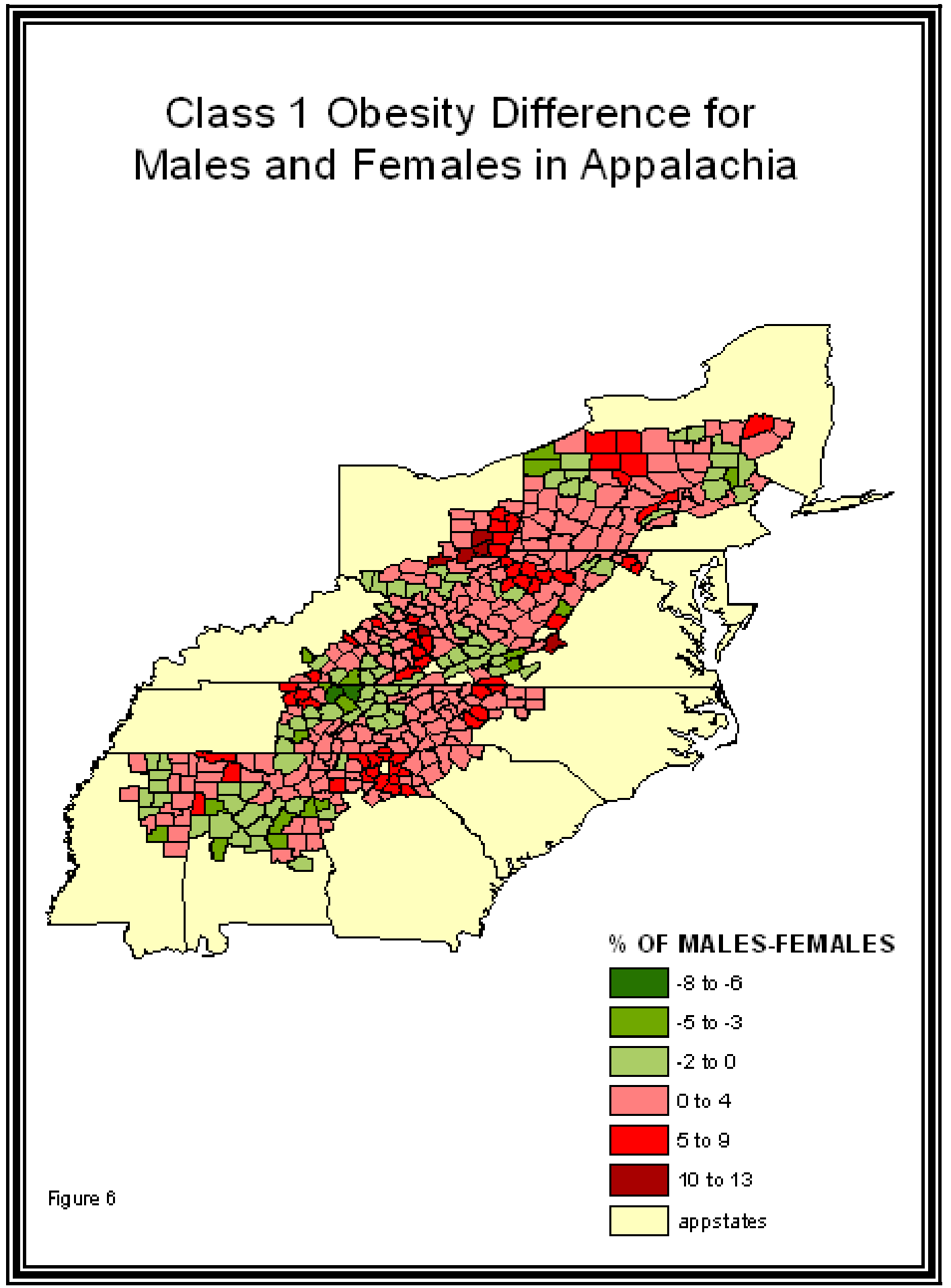

Figure 6: Class 1 obesity difference for males-females 


\section{Class 2 Adult obesity prevalence by gender}

Class 2 obesity prevalence rates (BMI of 35.0 to 39.9) for adult males and females are shown in Figures 7 and 8. Class 2 obesity prevalence ranged from $2 \%$ to $7 \%$ among males and $2 \%$ to $8 \%$ among females. Areas of high prevalence for males occur in central Appalachia, Pennsylvania/New York and Alabama. Areas of high prevalence for females occur primarily in central Appalachia, with somewhat lesser areas in central Pennsylvania and Alabama/Mississippi. Lowest rates for males occur in Georgia and Mississippi, and for females throughout much of the south. 


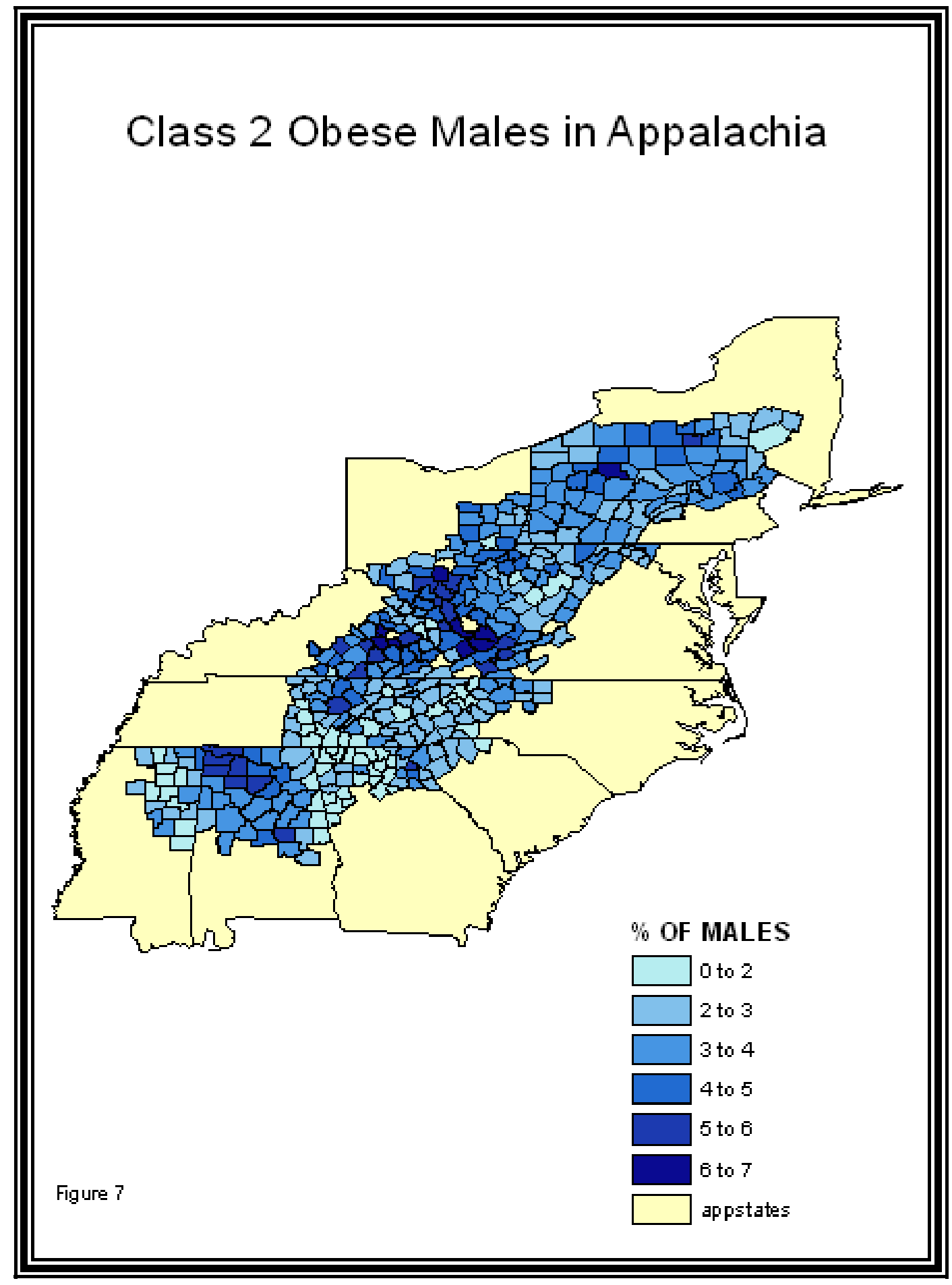

Figure 7: Percentage of class 2 obese males 


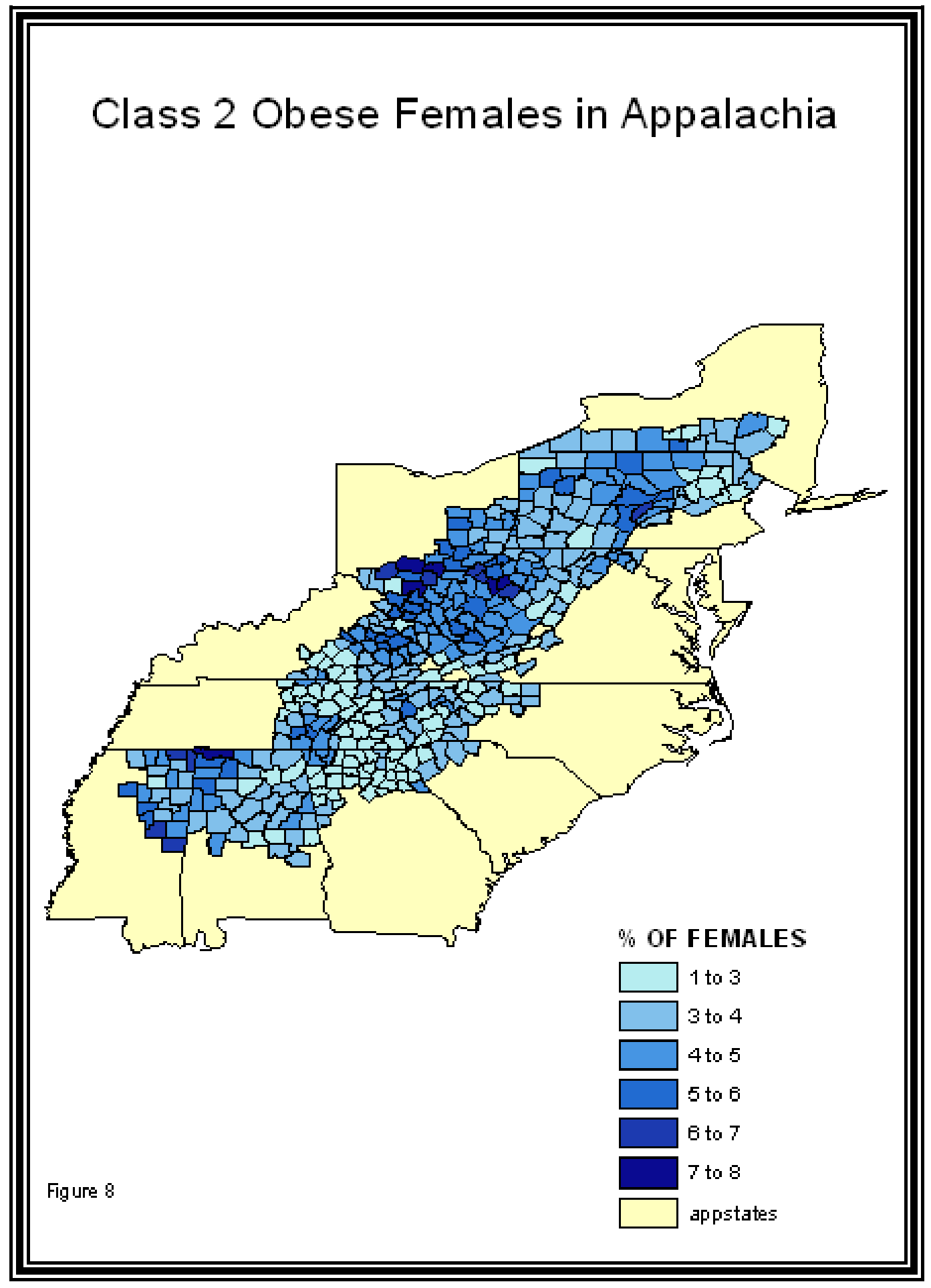

Figure 8: Percentage of class 2 obese females 


\section{Class 2 adult obesity male-female difference}

The class 2 obesity difference ranges from $-5 \%$ to $4 \%$ in Figure 9 . The map shows that class 2 female obesity is higher than class 2 male obesity for the great majority of counties in Appalachia, the opposite of the case for class 1 obesity. Areas with high obesity prevalence among males relative to females occur in Alabama and the border between Kentucky and Tennessee. Areas with particularly high obesity prevalence among females relative to males occur in central West Virginia, southern Ohio/northern Kentucky and Mississippi. 


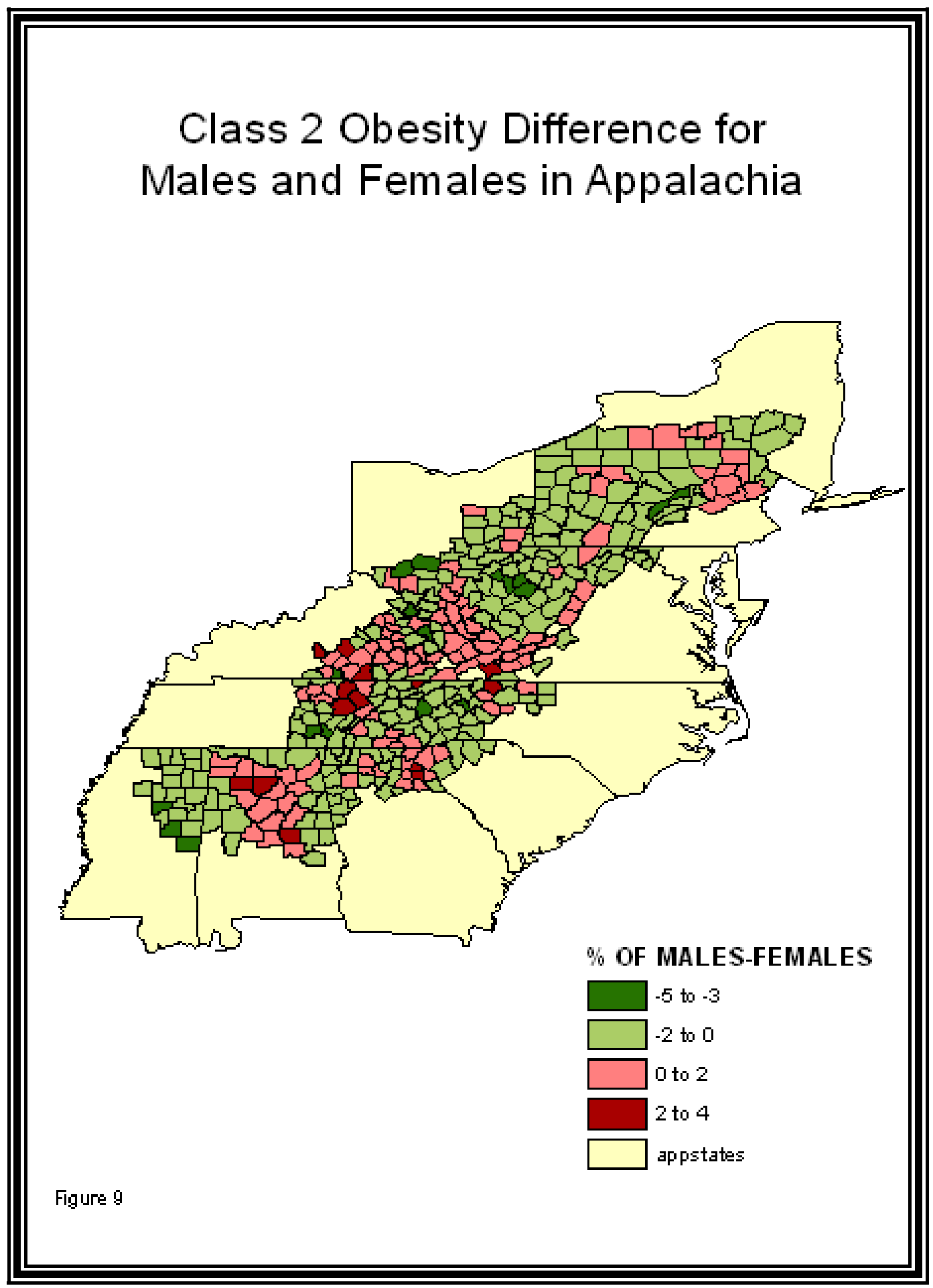

Figure 9: Class 2 obesity difference for males-femal 


\section{Chapter 4: Regression Model and Data}

\section{The Model}

This study uses a regression model to analyze the effect of a number of factors on obesity in Appalachia. Of the two compositional factors discussed in the literature, energy intake and energy expenditure (see chapter 2), only the latter was available for use in this study at the county level. Self-reported rates of physical inactivity can be obtained from the same BRFSS survey from which the obesity data were obtained. No energy (food) intake data are available.

The literature identifies five major contextual factors that have been shown to have an effect on obesity (see chapter 2): socioeconomic status/income, poverty, education, food availability and settlement form/location. Median family income as an indicator of socioeconomic status was found to be so strongly correlated with other variables in the model that it was considered inappropriate to use it. Poverty and education, however, are two factors that were retained in the model. Suitable data representing the fourth factor, food availability, could not be found for this study. The fifth contextual factor, settlement form/location, was represented in the model by the US Department of Agriculture codes used to categorize the urban-rural settlement form of each county in the US (see below for details).

In addition to the above factors discussed in the literature, it was decided to add two more contextual factors which could have a significant impact on obesity, employment change and labor force participation. Neither factor appears to have been considered in the literature on obesity before. Employment change indicates whether a 
county's economy is growing, stagnant or declining, which could very likely have an effect on the kind of decisions people make regarding energy intake and expenditure both physical and mental. Labor force participation indicates ability and/or motivation to work in the formal economy, which could also have a significant effect on energy intake and expenditure.

The model of obesity (with expected signs) is as follows:

$$
\begin{aligned}
\text { OBESITY }= & b_{1}+/-\sum b_{2-9} \text { URBRUR }_{2-9}-b_{10} \text { COLLEGE }+b_{11} \text { POVERTY }+b_{12} \text { INACTIV } \\
& -b_{13} \text { EMPLOY }-b_{14} \text { PARTICIP }
\end{aligned}
$$

OBESITY, the dependent variable in the model, is the aggregate obesity rate in a county over the period 1990 to 2000 . The model is estimated separately for males, females and the difference between males and females. The model is also estimated separately for three categories of obesity, overall obesity, class 1 obesity and class 2 obesity.

COLLEGE is the percent of a county's total population with a four year college education. The literature indicates that the relationship between COLLEGE and OBESITY should be negative. Obesity should decrease with increasing education.

POVERTY is the percent of a county's population in poverty. The literature indicates that the relationship between POVERTY and OBESITY should be positive. Obesity should increase with more poverty. 
INACTIV is the percent of a county's population that is physically inactive. The literature indicates that the relationship between INACTIV and OBESITY should be positive. Obesity should increase with higher rates of physical inactivity.

EMPLOY is the rate of change in a county's employment. The literature does not address this factor, but this research hypothesizes that EMPLOY is negatively related to OBESITY. Counties with dynamic economies will have healthier populations. Counties with stagnant or declining economies will have less healthy populations. Obesity is expected to be greater in counties with declining employment than in counties with growing employment.

PARTICIP is the participation rate of a county's adult population, by gender, in the labor force. Again, the literature does not address this factor. This research hypothesizes that PARTICIP is negatively related to OBESITY. Participation in the labor force indicates an active population. Obesity is expected to be greater in counties with lower labor force participation rates than in counties with higher rates.

$\sum b_{2-9}$ URBRUR $_{2-9}$ are eight dummy variables representing the varying urbanrural character of each county in Appalachia. The literature indicates that settlement form, usually represented by density, has an effect on obesity. This research hypothesizes this relationship in a different way. It argues that the varying urban-rural character of a county influences the obesity of the local population, but in a more complex way. The data for these dummy variables were obtained from the US Department of Agriculture, 
which categorizes every county in the US according to its urban-rural character. The USDA uses nine categories:

1. County in metro area with 1 million population or more

2. County in metro area of 250,000 to 1 million population

3. County in metro area of fewer than 250,000 population

4. Non-metro county with urban population of 20,000 or more, adjacent to a metro area

5. Non-metro county with urban population of 20,000 or more, not adjacent to a metro area

6. Non-metro county with urban population of $2,500-19,999$, adjacent to a metro area

7. Non-metro county with urban population of $2,500-19,999$, not adjacent to a metro area

8. Non-metro county all rural or less than 2,500 urban population, adjacent to metro area

9. Non-metro county all rural or less than 2,500 urban population, not adjacent to metro area

In this research, counties categorized as 1 were assigned to be the base or default category, and are therefore represented in the model by the intercept $b_{1}$. County types 2 through 9 are each represented by their own regression coefficient, $b_{2}$ through $b_{9}$. The 
specific relationship between obesity and each of these urban-rural categories is not hypothesized in this research, but is empirically determined by the model.

The regression model is estimated by ordinary least squares for six different dependent variables: overall obesity for males, overall obesity for females, class 1 obesity for males, class 1 obesity for females, class 2 obesity for males, and class 2 obesity for females.

\section{The Data}

As described in chapter 3, the county obesity data, OBESITY, were obtained from the Behavioral Risk Factor Surveillance System (BRFSS) and aggregated for the years 1993 through 1997. The measure of physical inactivity, INACTIV, is also derived from the BRFSS in response to the survey question: "During the past month, did you participate in any physical activities or exercises?" It too was aggregated for the years 1993 through 1997.

The variables COLLEGE, POVERTY and (gender specific) PARTICIP were each calculated as the county average for the years 1990 and 2000 (US Census Bureau, 1990, 2000). The variable EMPLOY was calculated as the rate of change in employment in a county between 1990 and 2000 (US Census Bureau, 1990, 2000). The urban-rural county categories, URBRUR, were obtained from the US Department of Agriculture (www.usda.gov). 


\section{Chapter 5: Results of Regression Analysis}

The regression model presented in the last chapter was estimated using Minitab for six different dependent variables for the 410 counties in Appalachia: overall obesity for males, overall obesity for females, class 1 obesity for males, class 1 obesity for females, class 2 obesity for males and class 2 obesity for females. The results are shown in Table 1. Coefficients significant at the 0.05 level are shown in bold.

Table 1: Appalachia Obesity Regression Results

\begin{tabular}{|c|c|c|c|c|c|c|}
\hline Variable & Obese M & Obese F & Obese1 M & Obese1 F & Obese2 M & Obese2 F \\
\hline Constant & $\mathbf{2 7 . 2}$ & $\mathbf{2 2 . 4}$ & $\mathbf{1 5 . 3}$ & $\mathbf{1 1 . 6}$ & $\mathbf{7 . 8}$ & $\mathbf{5 . 5}$ \\
\hline Urbrur2 & 1.04 & 0.99 & 1.01 & 0.69 & -0.08 & -0.09 \\
\hline Urbrur3 & $\mathbf{1 . 7 9}$ & 0.89 & $\mathbf{1 . 7 7}$ & 0.06 & -0.01 & -0.48 \\
\hline Urbrur4 & 1.22 & 1.26 & 1.45 & 0.70 & -0.06 & -0.53 \\
\hline Urbrur5 & 1.31 & 0.85 & 1.53 & 0.66 & -0.54 & -0.08 \\
\hline Urbrur6 & 1.05 & 0.89 & $\mathbf{1 . 3 6}$ & 0.60 & -0.36 & -0.01 \\
\hline Urbrur7 & $\mathbf{1 . 9 9}$ & 1.37 & $\mathbf{1 . 9 4}$ & 0.96 & -0.22 & -0.02 \\
\hline Urbrur8 & 1.22 & 0.36 & $\mathbf{1 . 4 5}$ & 0.31 & -0.30 & -0.05 \\
\hline Urbrur9 & 0.59 & 0.30 & $\mathbf{1 . 4 7}$ & 0.33 & -0.60 & -0.28 \\
\hline College & -0.044 & 0.006 & -0.021 & -0.016 & -0.017 & 0.007 \\
\hline Poverty & -0.034 & $\mathbf{0 . 0 9 5}$ & -0.023 & $\mathbf{0 . 0 9 3}$ & 0.0001 & 0.020 \\
\hline Employ & $\mathbf{- 0 . 0 2 2}$ & $\mathbf{- 0 . 0 3 5}$ & -0.008 & $\mathbf{- 0 . 0 2 4}$ & $\mathbf{- 0 . 0 0 9}$ & $\mathbf{- 0 . 0 0 8}$ \\
\hline Particip & $\mathbf{- 0 . 1 6 4}$ & $\mathbf{- 0 . 1 1 7}$ & $\mathbf{- 0 . 0 7 8}$ & -0.025 & $\mathbf{- 0 . 0 5 9}$ & $\mathbf{- 0 . 0 4 1}$ \\
\hline Inactiv & $\mathbf{0 . 0 4 8}$ & -0.025 & $\mathbf{0 . 0 6 7}$ & -0.002 & 0.00007 & -0.0003 \\
\hline R2 & $\mathbf{2 3 . 9 \%}$ & $\mathbf{3 2 . 0 \%}$ & $\mathbf{1 5 . 9 \%}$ & $\mathbf{2 4 . 0 \%}$ & $\mathbf{1 4 . 2 \%}$ & $\mathbf{1 3 . 4 \%}$ \\
\hline
\end{tabular}

Note: Coefficients significant at 0.05 level shown in bold

A number of interesting conclusions can be drawn from these results: 
1. INACTIV, the sole compositional variable in the model, is significant, for overall male and class 1 male obesity, and positively related to obesity, a result which supports previous research. Obesity is higher where people are more inactive. Why this variable is significant only for males and not for females is unknown and should obviously be researched further.

2. Of the contextual variables in the model, EMPLOY and PARTICIP have the biggest effect on obesity. This is an interesting finding, because the literature on obesity seems to have ignored both of these factors. Both relationships have the expected sign. EMPLOY is negatively related to obesity, which means that obesity is higher in counties with declining employment.

PARTICIP is also negatively related to obesity, which means that obesity is higher in counties where labor force participation is lower. The two factors have a significant effect for both males and females, and for almost all obesity categories. Judging by the coefficients, EMPLOY has a bigger effect on female obesity than on male obesity, and PARTICIP has a bigger effect on male obesity than on female obesity.

3. POVERTY is significant and positively related to obesity, supporting previous research. Obesity is higher where there is more poverty. Interestingly, however, poverty only has a significant impact on female obesity, and not on male obesity. In fact, the coefficients for male obesity are negative, though insignificant. Why poverty only affects females is unknown and needs further research. 
4. COLLEGE has no significant effect on obesity at all in this study. This is a surprising finding, considering that the literature generally finds education to have a very significant relationship with obesity.

5. URBRUR is significant, but only for male obesity. Overall male obesity is significantly higher in counties in a metro area of fewer than 250,000 population (category 3) and in non-metro counties with an urban population of 2,500-19,999 that are not adjacent to a metro area (category 7). Class 1 male obesity is significantly higher in counties in a metro area of fewer than 250,000 population (category 3 ), in non-metro counties with an urban population of 2,500-19,999 that are adjacent to a metro area (category 6), in non-metro counties with an urban population of 2,500-19,999 that are not adjacent to a metro area (category 7), in non-metro counties that are either all rural or with less than 2,500 urban population that are adjacent to a metro area (category 8) and in non-metro counties that are either all rural or with less than 2,500 urban population that are not adjacent to a metro area (category 9). In general, class 1 male obesity is higher in non-metro areas with small or no urban settlements. Given the more relaxed lifestyle of places such as these compared to energy-expending metro areas, these results are perhaps not surprising. It is curious, however, that both overall male obesity and class 1 male obesity are also significantly higher in small metro areas (category 3 ). Whether this is peculiar to Appalachia or not requires further research. 
Furthermore, it is unclear why settlement form does not play a significant role in female obesity. This too requires more research.

6. According to the explained variance, R2, the model performs best for overall obesity, somewhat less so for class 1 obesity, and worst for class 2 obesity. The model also generally performs better for females than for males. These results indicate that less is known about the causes of more extreme forms of obesity compared to more common forms of obesity. Also, less is known about the causes of male obesity than of female obesity.

\section{The regression residuals}

The standardized residuals for each of the six obesity models are shown in

Figures 10-15. The red areas throughout Appalachia represent counties where obesity is higher than it was predicted to be. The green areas throughout Appalachia represent counties where obesity is lower than it was predicted to be.

\section{Overall Obesity Residuals}

Figures 10 and 11 show the geographic distribution of residuals for overall male and female obesity. Figure 10 shows clusters of much higher than predicted overall male obesity in central Pennsylvania, southeastern Ohio, southern West Virginia/eastern Kentucky, north-west Alabama/Mississippi and north-east Georgia. Clusters of much lower than predicted overall male obesity are located in western and eastern Pennsylvania, central and northern West Virginia, Tennessee and north-west Georgia/north-east Alabama. 
Figure 11 shows clusters of much higher than predicted overall female obesity in central Pennsylvania, southern Ohio, southern West Virginia/eastern Kentucky, central Kentucky/central Tennessee and much of northern Alabama and Mississippi. Clusters of much lower than predicted overall female obesity are located in northern West Virginia, central Kentucky/Tennessee and a large contiguous area of eastern Tennessee, western North and South Carolina and northern Georgia. 


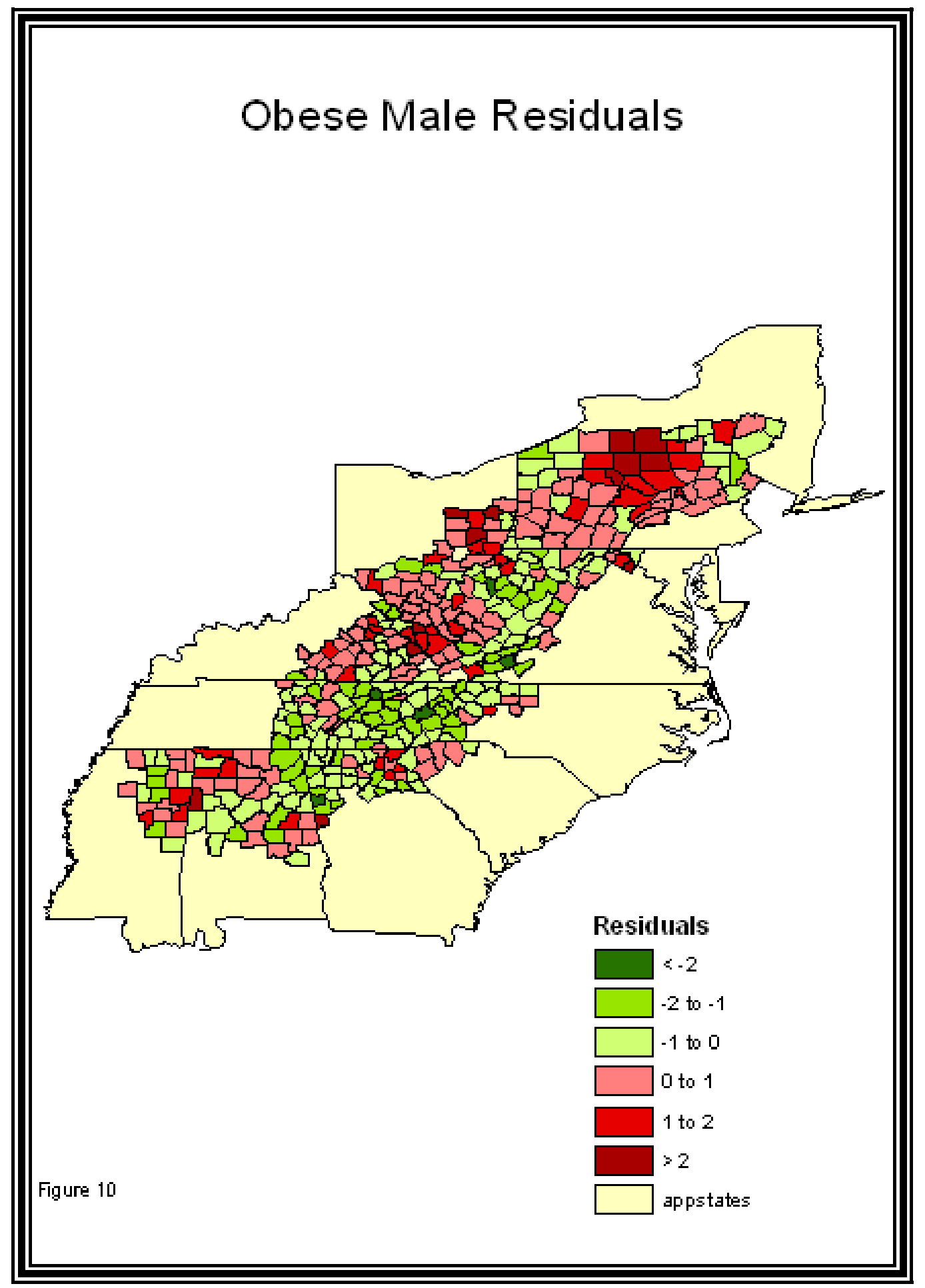

Figure 10: Overall obese male residuals 


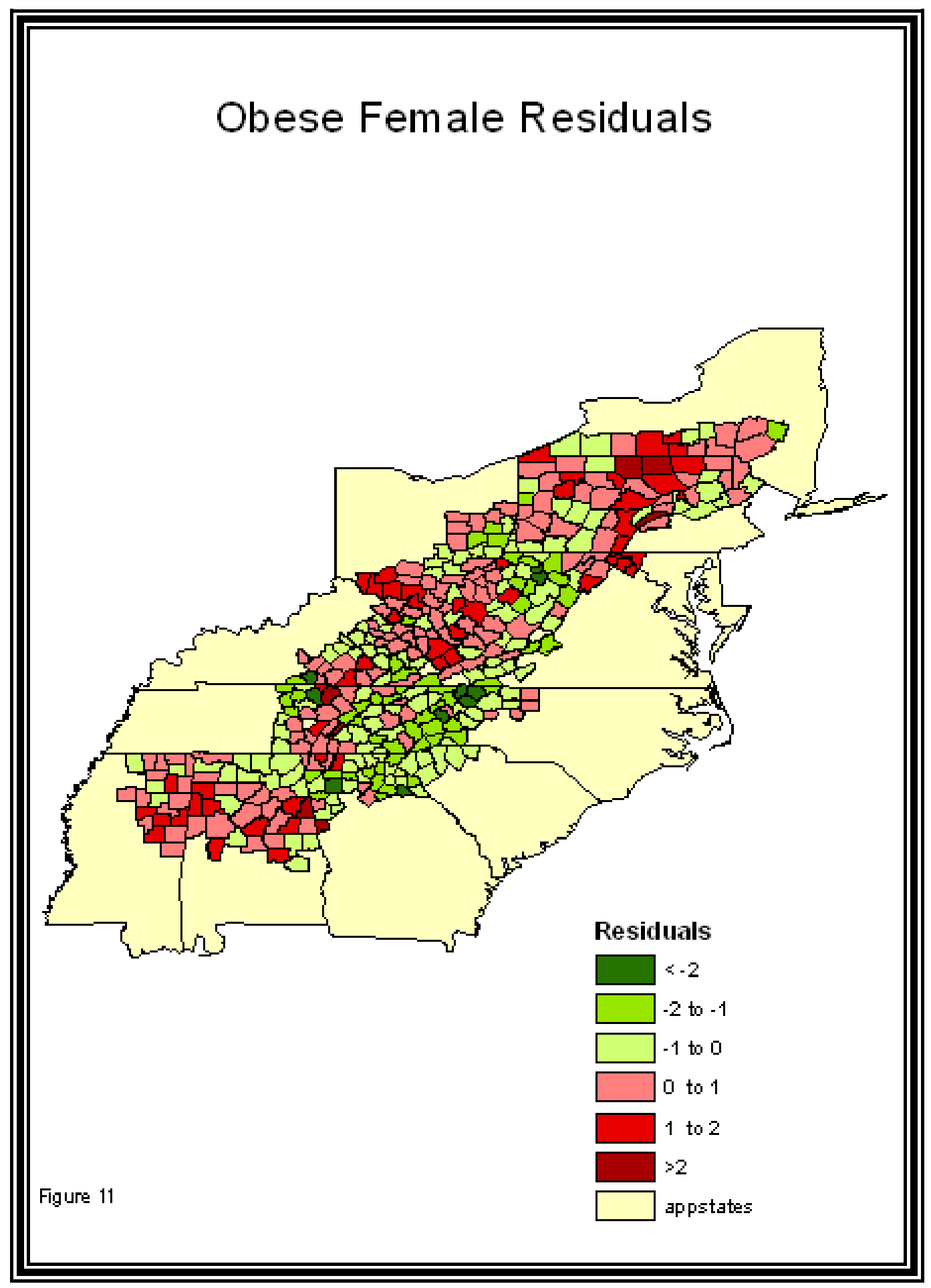

Figure 11: Overall obese female residuals 


\section{Class 1 Obesity Residuals}

Figures 12 and 13 show the geographic distribution of residuals for class 1 male and female obesity. Figure 12 shows clusters of much higher than predicted class 1 male obesity in central Pennsylvania, southeastern Ohio, southern West Virginia/eastern Kentucky, north-west Alabama/Mississippi and north-east Georgia. Clusters of much lower than predicted class 1 male obesity are located in western Pennsylvania and a large area extending from Alabama through Tennessee to southwest Virginia.

Figure 13 shows clusters of much higher than predicted class 1 female obesity in southern Ohio, southern West Virginia/eastern Kentucky, central Kentucky/central Tennessee and much of northern Alabama and Mississippi. Clusters of much lower than predicted class 1 female obesity are located in northern and central West Virginia, central Kentucky/Tennessee and eastern Tennessee/western North Carolina. 


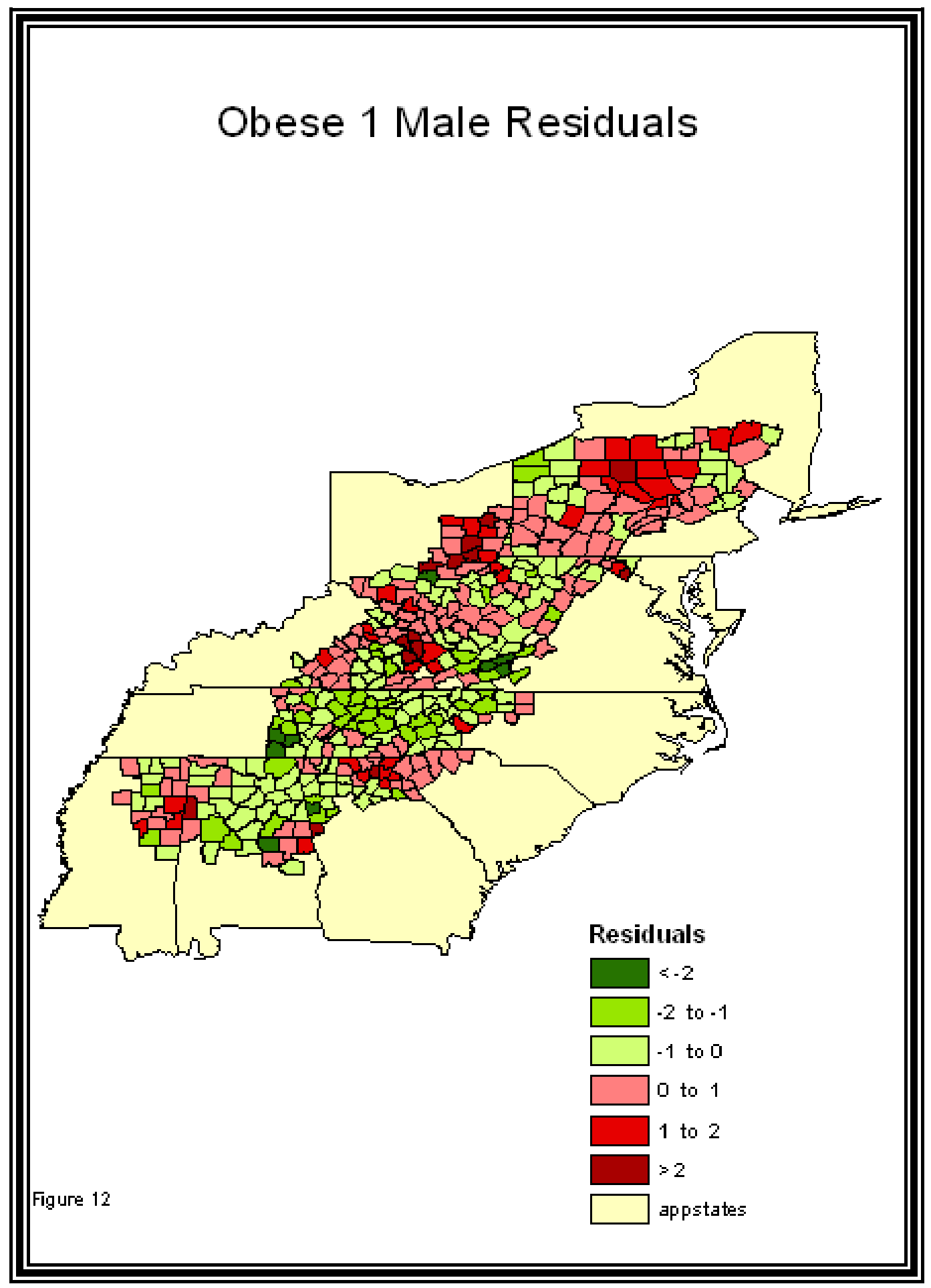

Figure 12: Class 1 obese male residuals 


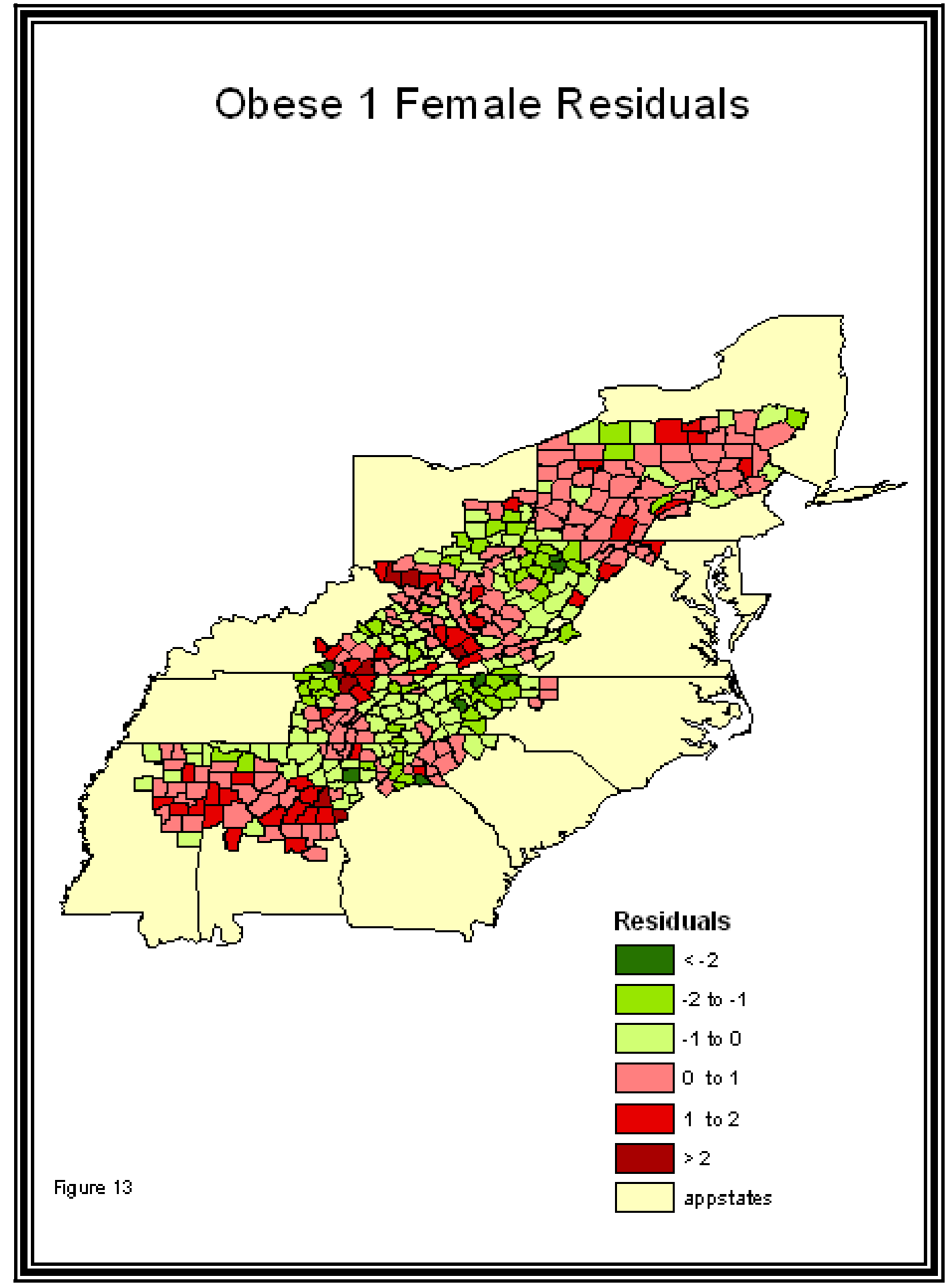

Figure 13: Class 1 obese female residuals 


\section{Class 2 Obesity Residuals}

Figures 14 and 15 show the geographic distribution of residuals for class 2 male and female obesity. Figure 14 shows clusters of much higher than predicted class 2 male obesity, in north-central Pennsylvania/western New York, an area extending from southern Ohio through southern West Virginia to eastern Kentucky, central Kentucky and north-west Alabama. Clusters of much lower than predicted class 2 male obesity are located in central West Virginia, north-east Mississippi and a large area extending from north-east Alabama through Georgia and Tennessee to western North and South Carolina.

Figure 15 shows clusters of much higher than predicted class 2 female obesity, in central Pennsylvania, much of Ohio and West Virginia, and north-west Alabama and Mississippi. Clusters of much lower than predicted class 2 female obesity are located in eastern Pennsylvania and a large area extending from Alabama through Georgia and Tennessee into southern Kentucky and southwest Virginia. 


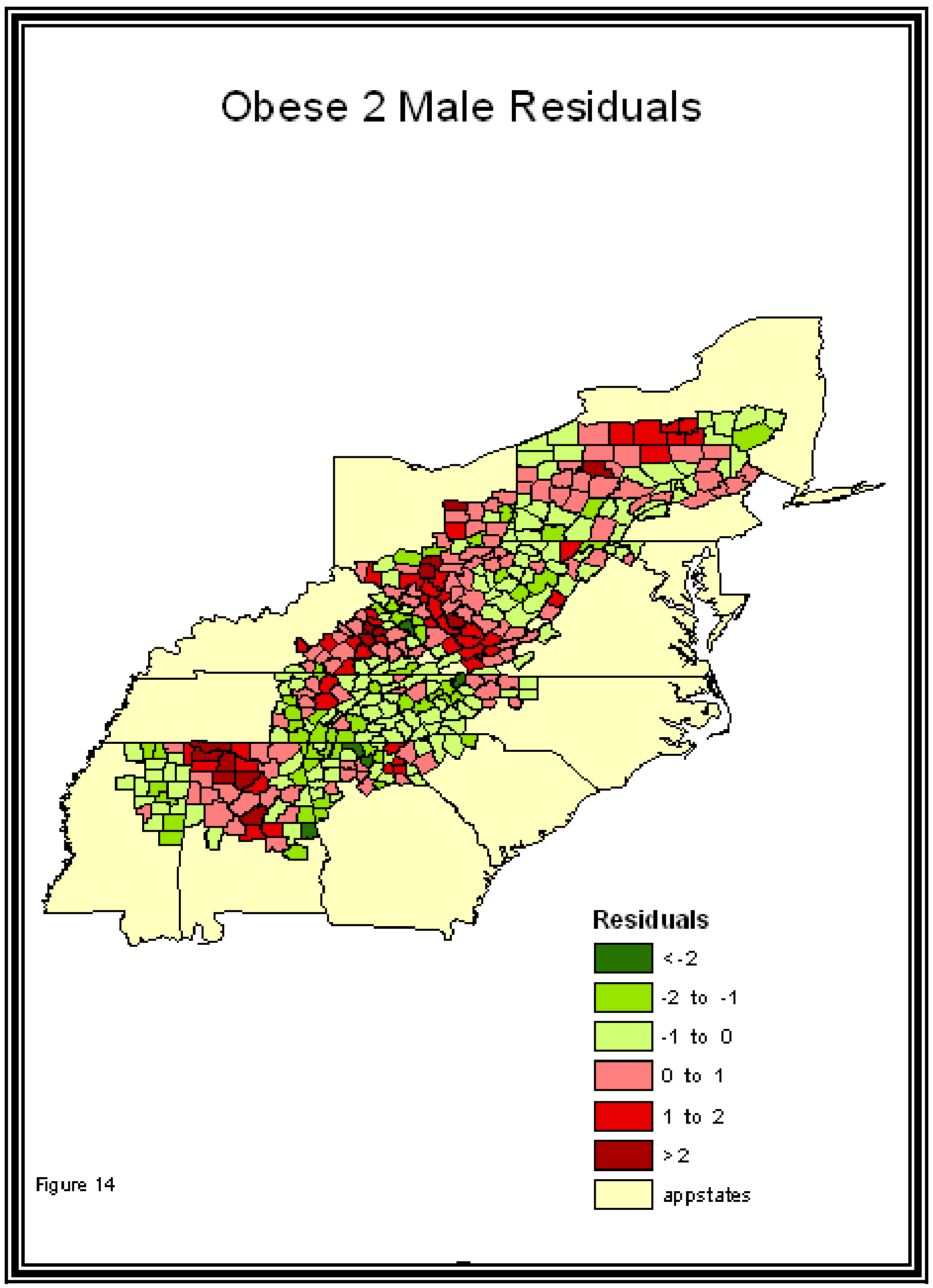

Figure 14: Class 2 obese male residuals 


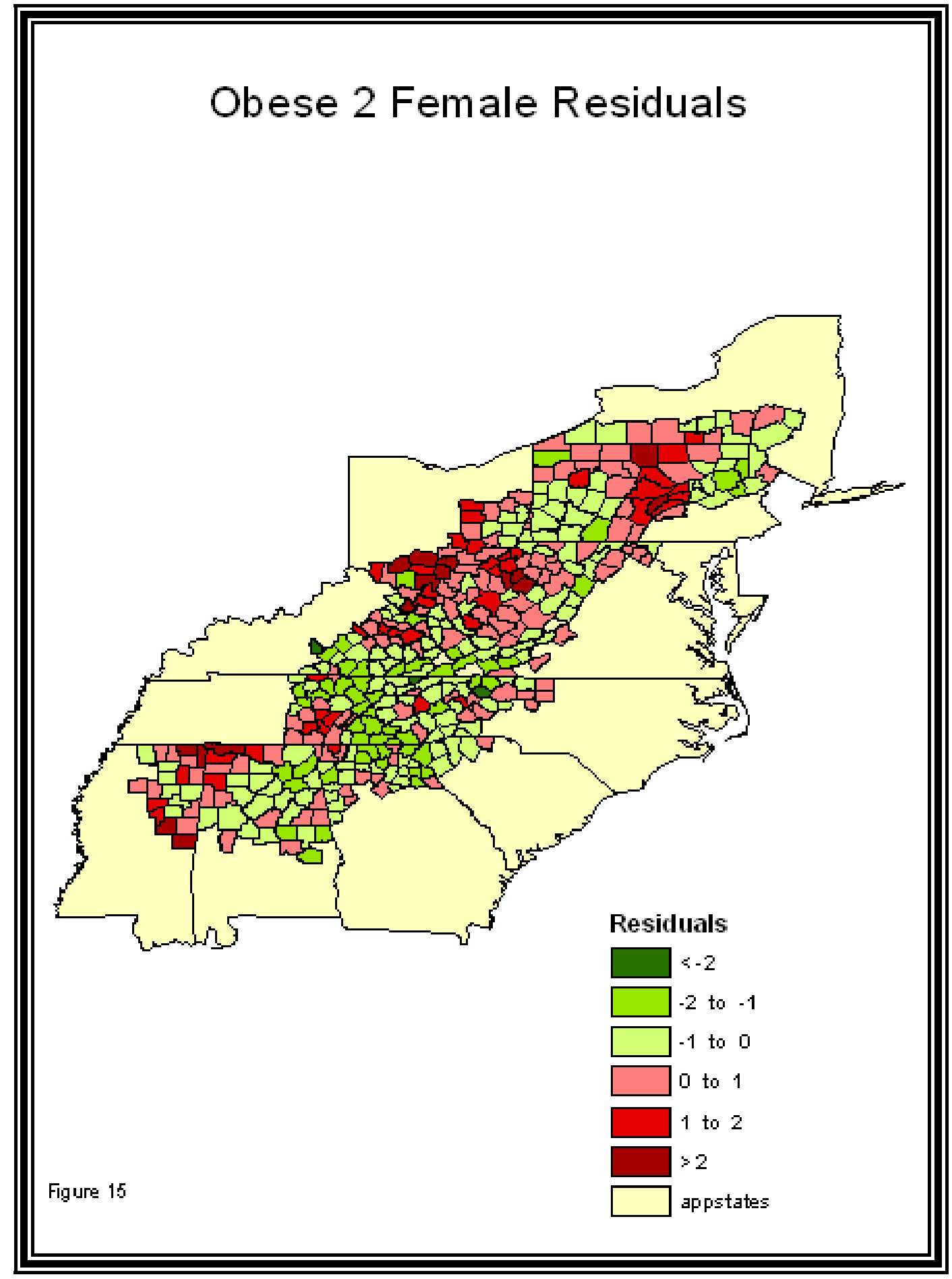

Figure 15: Class 2 obese female residuals 
Figure 14 shows clusters of much higher than predicted class 2 male obesity, in north-central Pennsylvania/western New York, an area extending from southern Ohio through southern West Virginia to eastern Kentucky, central Kentucky and north-west Alabama. Clusters of much lower than predicted class 2 male obesity are located in central West Virginia, north-east Mississippi and a large area extending from north-east Alabama through Georgia and Tennessee to western North and South Carolina.

Figure 15 shows clusters of much higher than predicted class 2 female obesity, in central Pennsylvania, much of Ohio and West Virginia, and north-west Alabama and Mississippi. Clusters of much lower than predicted class 2 female obesity are located in eastern Pennsylvania and a large area extending from Alabama through Georgia and Tennessee into southern Kentucky and southwest Virginia.

\section{Discussion}

There is a lot of evidence of clustering in the residuals from the six obesity models, both in terms of under-predicted obesity and over-predicted obesity. This evidence leads to two conclusions. First, spatial autocorrelation is present in all the regression models, which means that either the coefficient estimates may be biased or that the significance tests may be unreliable (inefficient). Further research can control for this spatial dependence by using a spatial regression model, which can be found in the GeoDa statistical package however, that is beyond the scope of this research.

Second, the residual clustering can mean that sub-regional or local factors play an important role in explaining the spatial distribution of obesity in Appalachia. Further 
research would have to involve a more locally-based, field-work oriented, intensive research design to identify these factors. Judging by the results of the regression models in Table 1, the spatial distribution of obesity in Appalachia remains largely unexplained and a lot of work still needs to be done to identify the factors responsible. 


\section{Chapter 6: Conclusions}

The prevalence of obesity has reached epidemic proportions in the United States and many parts of the world. There are various theories concerning the development of obesity, from the purely genetic to the purely environmental to a combination of the two. Generally, the chronic nature of obesity develops as a result of the interaction between an individual's genetic structure, cultural influences, lifestyle behaviors, and other environmental factors. This thesis documents disparities in the prevalence of obesity among counties in the Appalachian region. In addition, preliminary examinations are made to identify potential associations between geographic variability in the prevalence of obesity and the characteristics of individuals and places with variable prevalence rates. A number of important findings emerged from this report:

- The Appalachian maps demonstrate geographic variation in obesity prevalence, and specific counties consistently experience higher prevalence of obesity for both genders.

- Among areas with persistently high obesity prevalence rates, the burden is often highly localized among specific counties.

- Two significant contextual factors, employment change and labor force participation, were identified; however, they have or not been addressed in the literature.

- The regression model results demonstrate poverty has a significant impact on female obesity, but no significant impact on male obesity. 
- The sole compositional variable, inactivity, is gender specific for adult males in the Appalachian region.

- The regression model also found that urban-rural location is significant, but gender specific only for males in non-metro areas and small metro areas.

This thesis represents an exploratory initiative to identify the factors which are responsible for the spatial variation of adult obesity throughout the Appalachian region. Estimates of obesity prevalence for small geographic areas (counties) are often difficult to derive from existing survey data, thus, better results may be arrived at by obtaining accurate medical records. The data used in this study were derived in the 1990's and are therefore dated by this time. However, more recent data are harder to obtain due to disclosure constraints and regulations. Furthermore, there is insufficient data supporting the individual's compositional energy intake. For future research, an analysis can be implemented by using a spatial regression technique, which will control for the spatial autocorrelation trouble that occurred in this study. Also, more information can be derived about obesity by extending the analysis to other regions of the country. 


\section{List of References}

Adams, S.A., Der Ananian, C.A., DuBose, K.D., Kirtland, K.A., and Ainsworth, B.E. (2003). Physical activity levels among overweight and obese adults in South Carolina. Southern Medical Journal, 96(6), 539-543.

Adler, N.E., \& Ostrove, J.M. (1999). Socioeconomic status and health: What we know and what we don't know about socioeconomic status and health. Annual of the New York Academy of Science, 896, 3-15.

American Obesity Association (AOA). (2004). AOA fact sheets: Obesity in the U.S. Retrieved from http://www.obesity.org/subs/fastfacts/obesity_US.shtml

Andersen, R. E., Frankowiak, S., Christmas, C., Walston, J., \& Crespo, C. (2001). Obesity and reports of no leisure time activity among older Americans: Results from the third national health and nutrition examination survey. Educational Gerentology, 27, 297-306.

Bernstein, M.S., Costanza, M.C., \& Morabia, A. (2003). Association of physical activity intensity levels with overweight and obesity in a population-based sample of adults. American Health Foundation and Elsevier Inc., 38, 94-104.

Binkley, J.K., Eales, J., \& Jekanowski, M. (2000). The relation between dietary change and rising US obesity. International Journal of Obesity Related Metabolic Disorders, 24(8), 1032-1039.

Burton, N.W., Turrell, G., \& Oldenburg, B. (2003). Participation in recreational physical activity: Why do socioeconomic groups differ? Health Education \& Behavior, 30(2), 225-244.

Casper, M. L., Barnett, E., Halverson, J. A., Elmes, G. A., Braham, V. E., Majeed, Z., Bloom, A., \& Stanley, S. (2000). Women and heart disease: An atlas of racial and ethnic disparities in mortality. Morgantown, WV: West Virginia University, Office of Social Environment and Health Research.

Casper, M. L., Barnett, E., Halverson, J. A., Elmes, G. A., Braham, V. E., Majeed, Z., Bloom, A., \& Stanley, S. (2001). Men and heart disease: An atlas of racial and ethnic disparities in mortality. Morgantown, WV: West Virginia University, Office of Social Environment and Health Research.

Centers for Disease Control (2005). Preventing Obesity and Chronic Diseases Through Good Nutrition and Physical Activity. Retrieved from http://www.cdc.gov/nccdphp/publications/factsheets/Prevention/obesity.html 
Contaldo, Franco and Pasanisi, Fabrizio. (2003). Obesity epidemics: secular trend or globalization consequences? Beyond the interaction between genetic and environmental factors. Clinical Nutrition, 23, 289-291.

Crespo, C. \& Arbesman, J. (2003). Obesity in the United States. The Physician \& Sportsmedicine, 31(11), 23-28.

Drewnowski, A. \& Specter, S.E. (2004). Poverty and obesity: The role of energy density and energy costs. American Journal of Clinical Nutrition, 79(1), 6-16.

Ewing R., Schmid T., Killingsworth R., Zlot A., \& Raudenbush S. (2003). Relationship between urban sprawl and physical activity, obesity, and morbidity. American Journal of Health Promotion, 18(1), 47-57.

Ferraro, K. F., Su, Y., Gretebeck, R. J., Black, D. R., \& Badylak, S. F. (2002). Body mass index and disability in adulthood: A 20 year panel study. American Journal of Public Health, 92(5), 834-840.

Flegal, K. M., Carroll, M D., Ogden, C. L., and Johnson, C. L. (2002). Prevalence and Trends in Obesity Among US Adults, 1999-2000. Journal of the American Medical Association, 288(14), 1723-1727.

Ford, E.S., Moriarty, D.G., Zack, M.M., Mokdad, A.H., \& Chapman, D.P. (2001). Selfreported body mass index and health related quality of life: Findings from the behavioral risk factor surveillance system. Obesity Research, 9(1), 21-31.

Fox, M. (2004). Obesity gains on smoking as top cause of death. Retrieved from http://www.rense.com/general50/0ob.html

Frank, L.D., Andresen, M.A., and Schmid, T.L. (2004). Obesity relationships community design, physical activity, and time spent in cars. American Journal of Preventive Medicine, 27(2), 87-96.

French, S.A. (2003). Symposium: sugar and fat-from genes to culture. Pricing effects on food choices. Journal of Nutrition, 133, 841-843.

Frenn, M. \& Malin, S. (2003). Diet and exercise in low-income culturally diverse middle school students. Public Health Nursing, 20(5), 361-368.

Friedman, J. M. (2003). A war on obesity, not the Obese. Science, 299, 856-858.

Halverson, J. A., Ma, L., Harner, E. J., Hanham, R. Q., \& Braham, V. E. (2004). Adult Obesity in Appalachia: An Atlas of Geographic Disparities. West Virginia University, Morgantown, WV: September 2004. 
Hill, J.O. \& Peters, J.C. (1998). Environmental contributions to the obesity epidemic. Science, 280, 1371-1374.

Holm, K., Li, S., Spector, N., Hicks, F., Carlson, E., \& Lanuza, D. (2001). Obesity in adults and children: a call for action. Journal of Advanced Nursing, 36(2), 266-269.

Humpel, N., Owen, N., \& Leslie, E. (2002). Environmental Factors Associated With Adults' Participation in Physical Activity. American Journal of Preventive Medicine, 22(3), 188-199.

James, P.T., Leach, R., Kalamara, E., \& Shayeghi, M. (2001). The worldwide obesity epidemic. Obesity Research, 9(4), 228-233.

Jeffery, R.W., Wing, R.R., Sherwood, N.E., \& Tate, D.F. (2003). Physical activity and weight loss: does prescribing higher physical activity goals improve outcome? American Society for Clinical Nutrition, 78, 684-689.

Kahn, H.S., Williamson, D.F., \& Stevens, J.A. (1991). Race and weight change in US women: The roles of socioeconomic and marital status. American Journal of Public Health, 81(3), 319-323.

Larkin, M. (2003). Can cities be designated to fight obesity? The Lancet, 362, 10461047.

Ma, L. (2004). Obesity in West Virginia: A regional analysis. 1-24.

McCann, B. \& Ewing, R. (2003). Relationship between urban sprawl and physical activity, obesity and morbidity. Contra Costa Times. 77, 114-133.

Mcinnis, K.J., Franklin, B.A., \& Rippe, J.M. (2003). Counseling for Physical Activity in Overweight and Obese Patients. American Family Physician, 67(6), 1249-1256.

Milloy, S. (2005). Obesity hysteria survives despite official debunking. Junk Science Judo.

Mokdad, A., Bowman, B. A., Ford, E. S., Vinicor, F., Marks, J. S., \& Koplan, J. P. (2001). The Continuing Epidemics of Obesity and Diabetes in the United Sates. JAMA, 286(10), 1195-1200.

Monteiro, C.A., Conde, W.L., \& Popkin, B.M. (2001). Independent effects of income and education on the risk of obesity in the Brazilian adult population. Journal of Nutrition, 131, 881-886.

Applebome, P. (1999) For better and worse, poverty's poster child. New York Times. Retrieved from http://www.ncpa.org/pd/economy/pd071299g.html/ 
Nestle, M. (2000). Changing the diet of a nation: Population/regulatory strategies for a developed economy. Asia Pacific J Clin Nutr, 9, 33-40.

Nestle, M. \& Jacobson, M. F. (2000). Halting the Obesity Epidemic: A public health policy approach. Public Health Reports, 115, 12-21.

Newman, C. (2004). Why are we so fat? National Geographic, 48-61.

Observer-Reporter. Associated Press. Obesity increases risk for nine types of cancers. Tuesday, August 24, 2004.

Ogden, C.L., Flegal, K.M., Carroll, M.D., \& Johnson, C.L. (2002). Prevalence and trends in overweight among US children and adolescents. JAMA, 288(14), 1728-1732.

Owen, N., Humpel, N., Leslie, E., Bauman, A., \& Sallis, J. F. (2004). Understanding environmental influences on walking. American Journal of Preventive Medicine, 27(1), 67-76.

Paeratakul, S., Lovejoy, J.C., Ryan, D.H., \& Bray, G.A. (2002). The relation of gender, race and socioeconomic status to obesity and obesity comorbidities in a sample of US adults. International Journal of Obesity Related Metabolic Disorders, 26(9), 1205-1210.

Personal MD. (1998). Diabetes + Obesity Up Cancer Risk. Retrieved from http://www.personalmd.com/news/a1998072903.shtml

Pickle, W. \& Su, Y. (2002). Within-state geographic patterns of health insurance coverage and health risk factors in the United States. American Journal of Preventive Medicine, 22(2), 75-83.

RAND Corporation. (2004). Obesity and Disability: The Shape of Things to Come. Retrieved from http://rand.org/publications/RB/RB9043/html

Ravussin, E. \& Danforth, E. (1999). Beyond sloth-physical activity and weight gain. Academic Search Elite, 283(5399), 1-4.

Reeves, G. K., Pirie, K., Beral, V., Green, J., Spencer, E., \& Bull, D. (2008). Cancer incidence and mortality in relation to body mass index in the Million Women Study: cohort study. Retrieved from http://www.bmj.com.html

Reuters (2002)(a). Obesity double bowel cancer risk in women study. Yahoo! News. Retrieved from http://news.yahoo.com/news?tmpl=st...m/health_bowelcancer_dc_1\&printer=1

Reuters (2002)(b). Obesity double colon cancer risk in young women. Yahoo! News. Retrieved from http://story.news.yahoo.com/news?tm.../hl_nm/obesity_women_dc_1\&printer=1 
Reuters (2003). Obesity behind 90,000 cancer deaths each year. Yahoo! News. Retrieved from

http://www.12.42.224.150/HealthNews/Reuters/NewsStory042320032.html

Reuters (2004). Study: Obesity threatens health care system. Yahoo! News. Retrieved from http://www.cnn.com/2004/HEALTH/12/08/obesity.healthcare.reut/index.html

Richwine, L. (2004). Obesity rising among poor in developing world-study. Retrieved from http://in.news.yahoo.com/040603/137/2dg9p.html

Sciamanna, C.N., Tate, D.F., Lang, W., \& Wing, R.R. (2000). Who reports receiving advice to lose weight? Arch Intern Med, 160, 2334-2339.

Sobal, J. \& Stunkard, A.J. (1989). Socioeconomic status and obesity: A review of the literature. Psychological Bulletin, 105(2), 260-275.

Sturm, R. \& Wells, K. B. (2001). Does obesity contribute as much to morbidity as poverty or smoking? Public Health, 115, 229-235.

Thorogood, M. (1998). Combining diet with physical activity in the treatment of obesity. Journal of Human Nutrition and Dietetics, 11, 239-242.

United States Department of Agriculture (USDA). Retrieved from http://www.usda.gov

U.S. Department of Health and Human Services \& Centers for Disease Control and Prevention. (1999). Chronic diseases and their risk factors: The nation's leading causes of death. (pp.533-941). Washington, DC: U.S. Government Printing Office.

U.S. Department of Health and Human Services. (2000). Healthy people $2010\left(2^{\text {nd }}\right.$ edition) with understanding and improving health and objectives for improving health. Washington, DC: US Government Printing Office.

U.S. Department of Health and Human Services (2001). The Surgeon General's call to action to prevent and decrease overweight and obesity 2001. Washington, DC: US Government Printing Office. 